\title{
Efectos de la declaración de inconstitucionalidad parcial del IIVTNU tras la sentencia interpretativa dictada por el Tribunal Supremo en $2018^{1}$
}

\section{Effects of the declaration of partial unconstitutionality of IIVTNU after the interpretive judgment issued by the Supreme Court in 2018}

\author{
Joan Pagès i Galtés \\ Universitat Rovira i Virgili (España) \\ ORCID: https://orcid.org/0000-0002-4287-6110
}

joanpg38@gmail.com

\section{NOTA BIOGRÁFICA}

Doctor en Derecho por la Universidad de Barcelona. Secretario de Ayuntamiento, en excedencia. Catedrático de Derecho financiero de la Universitat Rovira i Virgili. Miembro de la Comissió Jurídica Assessora de la Generalitat de Catalunya. Línea de investigación centrada en la financiación local y autonómica.

\begin{abstract}
RESUMEN
Desde la instauración en 1919 del usualmente denominado impuesto municipal de plusvalía hasta la entrada vigor de la Ley reguladora de las Haciendas Locales de 1988, la determinación del incremento de valor como elemento integrante de su hecho y base imponible había generado muchos problemas, pero todos esencialmente eran de adecuación de las Ordenanzas fiscales a la ley. En cambio, tras la entrada en vigor de la citada Ley de 1988, los principales problemas que se han presentado son de adecuación de la ley a la Constitución. Tanto ello es así, que en 2017 el TC ha dictado doctrina declarando la inconstitucionalidad parcial del impuesto. Se da empero la circunstancia que se ha generado otro problema, cual es el de la concreción de los efectos de semejante declaración parcial de inconstitucionalidad. Dadas las dudas que ello plantea, el TS ha dictado en 2018 una sentencia por la que se interpretan algunos aspectos básicos de la doctrina constitucional.
\end{abstract}

\section{PALABRAS CLAVE}

Base imponible; ficción jurídica; Impuesto sobre el Incremento de Valor de los Terrenos de Naturaleza Urbana; Impuesto municipal de plusvalía; presunción; ingresos indebidos; interpretación; sujeción; responsabilidad patrimonial; revisión.

\section{ABSTRACT}

Since the establishment in 1919 of the municipal capital gain tax until the approval of the Law regulating the Local Treasuries of 1988, the determination of the increase in value as an integral element of its chargeable

\footnotetext{
1 Este trabajo que, debe reconocerse, asume el criterio de la dra. M. T. DIVI i TORNS (prof. as. de la UB) sobre el tema de la suspensión del procedimiento, se centra en la la ponencia del autor expuesta el día 10 de julio de 2018, en la "XI Setmana Municipal", celebrada por la Associació Catalana de Municipis, bajo la dirección de la dra. J. GIFREU FONT (profesora titular de la UAB i directora de la Càtedra Enric Prat de la Riba d'Estudis Jurídics) y la coordinación de los drs. J. R. FUENTES i GASÓ (profesor titular de la URV i director de la Càtedra d'Estudis Jurídics Màrius Viladel i Martín) y M. PERETÓ i GARCÍA (profesora titular de la UAB i directora general de Planificació i Estudis Fiscals de la Generalitat de Catalunya).
} 
event and tax base had generated many problems, but all were of adaptation of the tax Ordinances to the law. Instead, after the approval of the 1988 Law, the main problems that have arisen are the adaptation of the law to the Constitution. So that, in 2017 the constitutional Court has established doctrine declaring the partial unconstitutionality of the tax. This circumstance, however, has generated another problem, which is the concretion of the effects of this partial declaration of unconstitutionality. In view of the doubts that this generates, the Supreme Court has issued in 2018 a judgment interpreting some basic aspects of constitutional doctrine.

\section{KEYWORDS}

Tax base; legal fiction; Tax on Value Increase of Urban Land; municipal capital gain tax; presumption; undue income; interpretation; subjection; patrimonial responsibility; revision.

\section{SUMARIO}

1. MARCO NORMATIVO. 2. NATURALEZA DEL SISTEMA CUANTIFICADOR DEL INCREMENTO DE VALOR. 3. DECLARACIÓN DE INCONSTITUCIONALIDAD. 4. EFECTOS MATERIALES Y FORMALES DE LA DECLARACIÓN DE INCONSTITUCIONALIDAD. LA INTERPRETACIÓN DEL TS. 5. INCREMENTOS DE VALOR INEXISTENTES VERSUS INCREMENTOS DE VALOR ESCASOS. 6. TRANSMISIONES REALIZADAS TRAS LA DECLARACIÓN DE INCONSTITUCIONALIDAD. 7. TRANSMISIONES REALIZADAS ANTES DE LA DECLARACIÓN DE INCONSTITUCIONALIDAD. 8. INGRESOS INDEBIDOS. 9. PROCEDIMIENTOS ESPECIALES DE REVISIÓN. 10. RESPONSABILIDAD PATRIMONIAL Y COMPENSACIONES ECONÓMICAS. 11. CONCLUSIONES.

\section{MARCO NORMATIVO}

\subsection{Antecedentes}

Según explica REBÉS i SOLÉ², la figura impositiva que nos ocupa, tradicionalmente denominada «Arbitrio o Impuesto de Plusvalía», «aparece a principios de siglo [siglo XX] con la finalidad de dotar a los Ayuntamientos de más importantes ingresos, a base de gravar los incrementos de valor que obtuviesen las fincas que resultasen beneficiadas por las reformas urbanas». Este impuesto ya estaba previsto en algunos proyectos normativos que no llegaron a entrar en vigor ${ }^{3}$, pero no se estableció hasta el RD de 13 de marzo de 1919. A partir de aquí fue objeto de varias reformas llegando al TRR de $1986^{4}$ que estuvo en vigor hasta que se aprobó la LRHL de $1988^{5}$.

Lo que a nuestros efectos más nos interesa es que en esta etapa el Impuesto pretendía gravar el incremento real del valor del inmueble acaecido en un concreto período de tiempo a raíz de la acción urbanística pública, cosa para la cual era necesario determinar los valores inicial y final del inmueble en el período temporal a considerar. En esta etapa, lo único que esencialmente varió fue el método de determinación, pues mientras el citado RD de 13 de marzo de 1919, contemplaba sólo la estimación directa, tras la Real Orden de 19 de octubre de 1921 se contempló la posibilidad de que los Ayuntamientos determinaran este incremento de forma objetiva mediante la aprobación de unos índices de valores. Criterio de determinación objetivo que se desarrolló por el Estatuto Municipal de 1924 y devino obligatorio para los Ayuntamientos con el RD-Ley de 3 de noviembre de $1928^{6}$.

\footnotetext{
2 J. E. REBÉS i SOLÉ, 1987, págs. 358 y ss.
}

${ }^{3}$ Nos referimos a los denominados Proyectos de ley Maura (1907), Canalejas-Cobian (1910), Bagallad (1915), Alba (1916) y González Besada (1918). abril.

${ }^{4}$ Texto refundido de las disposiciones legales vigentes en materia de Régimen Local, aprobado por RD Leg. 781/1986, de 18 de

${ }^{5}$ Ley 39/1988, de 28 de diciembre, reguladora de las Haciendas Locales.

${ }^{6}$ Explican J. LÓPEZ y J. VERA, 2018, pág. 81, que:

«Desde 1924 hasta la promulgación de la Ley 39/1988 de Haciendas Locales el cálculo del incremento de valor se obtenía mediante la aplicación de la siguiente fórmula:

$\Delta \mathrm{V}=\mathrm{Vf}-(\mathrm{Vo}+\mathrm{VM}+\mathrm{Cf} \mathrm{CE})$

Siendo: 
REALA. Nueva Época - N.o 11, Abril-Septiembre 2019 - ISSN: 1989-8975 - DOI: 10.24965/reala.v0i11.10579 - [Págs. 156-183]

Efectos de la declaración de inconstitucionalidad parcial del IIVTNU tras la sentencia interpretativa dictada por el tribunal supremo..

Joan Pagès i Galtés

Se trataba de un sistema coherente con el objeto del tributo (gravar los incrementos de valor de los terrenos) y respetuoso con los principios tributarios (la determinación objetiva del incremento de valor se basaba en datos capaces de ajustarse a la capacidad económica). El problema que presentaba es que la fijación de los índices por parte de la Corporación municipal era objeto de una alta litigiosidad en relación a la motivación de los índices?

\subsection{LRHL de 1988}

Esta circunstancia es la única que, a nuestro modo de ver, racionalmente explica el cambio de criterio del legislador. En efecto, el TRRL de 1986 fue derogado por la LRHL de 1988, donde se estableció el actual Impuesto sobre el Incremento de Valor de los Terrenos de Naturaleza Urbana (IIVTNU). Este impuesto también pretende gravar el incremento real del valor del inmueble, pues según la Exposición de Motivos de la LRHL presenta la «misma naturaleza y análoga denominación» del impuesto que viene a sustituir, su hecho imponible también es parejo (cfr. art. 105.1) y a la hora de definirse la base imponible en la redacción original del artículo 108.1 se decía explícitamente que estaba constituida por el incremento «real» del valor de los terrenos.

Se da empero la circunstancia que la determinación de la base imponible ya no se hace mediante la diferencia entre los valores inicial y final calculados de forma objetiva a través de índices, sino que a partir de la nueva LRHL de 1988 se arbitra un sistema aún más objetivo, cabiendo calificarlo de "forfatario», pues tratándose de una trasmisión de terrenos la base imponible se cuantifica mediante una simple fórmula matemática consistente en multiplicar el valor catastral del suelo de la finca en la fecha de la transmisión por el número de años transcurridos desde la última transmisión y por el coeficiente aprobado por el Ayuntamiento según la tabla establecida por el legislador ${ }^{8}$. El carácter forfatario se refuerza cuando en el artículo 111.4 de la LRHL se establece con motivo de la habilitación a los Ayuntamientos para exigir el impuesto en régimen de autoliquidación que: «[...] Respecto a dichas autoliquidaciones, el Ayuntamiento correspondiente sólo podrá comprobar que se han efectuado mediante la aplicación correcta de las normas reguladoras del impuesto, sin que puedan atribuirse valores, bases o cuotas diferentes de las resultantes de tales normas». Y, en fin, el carácter forfatario aún se vio más reforzado cuando la Ley 51/2002, de 27 de diciembre, de reforma de la LRHL, modificó el artículo 108.1 de la LRHL a los efectos de hacer desaparecer el término «real» que calificaba al incremento objeto de gravamen.

Este nuevo sistema, que ha sido recogido por el vigente $\mathrm{TR}$ de la $\mathrm{LRHL}^{9}$, ciertamente resuelve el problema de la litigiosidad derivada de la aprobación de los índices, pero plantea un problema aún más grave cual es el de su constitucionalidad. Nos explicamos, con el sistema de índices aplicable hasta la derogación del TRRL de 1986, el problema se circunscribía a enjuiciar si los índices aprobados por cada Ayuntamiento estaban suficientemente motivados. Se trataba, por tanto, de una cuestión de adecuación de la Ordenanza fiscal a la ley. En cambio con el nuevo sistema implantado por la LRHL de 1988, el problema afecta a la misma ley, pues su aplicación siempre determina matemáticamente un incremento de valor $\mathrm{y}$, por ende, cabe discutir si se ajusta a los principios constitucionales de capacidad económica, no confiscatoriedad e interdicción de la indefensión.

Vf, el valor corriente en venta al terminar el período de imposición, determindo de acuerdo con los índices o tipos fijados por los Ayuntamientos.

Vo, el valor inicial deteminado de acuerdo con los índices o tipos fijados por los Ayuntamientos.

$\mathrm{VM}$, el valor de las mejoras permanentes.

Cf, el porcentaje de las contribuciones especiales satisfechas imputables al terreno de acuerdo con la antigüedad de la finca.

$\mathrm{CE}$, importe de las contribuciones especiales satisfechas».

7 Y es que, como explica E. SIMÓN ACOSTA, 1987, pág. 438, los índices que aprobara la Corporación debían estar motivados, pues caso contrario pecarían de nulidad. En este marco, explican J. LÓPEZ y J. VERA, 2018, pág. 81, que «Los índices, como era de prever, fueron objeto de muchísimas reclamaciones: tanto mediante su impugnación directa, cuando estos eran expuestos al público durante la tramitación de la Ordenanza, como cuando, en los expedientes de liquidación, se giraban las correspondientes cuotas a los contribuyentes».

${ }^{8}$ Explican J. LÓPEZ y J. VERA, 2018, pág. 81, que éste es el «Sistema de obtención del incremento de valor a partir del 1-01-90: $\Delta \mathrm{V}=\mathrm{N} \times \mathrm{Ci} \times \mathrm{Vs}$

$\mathrm{N}$, número de años transcurridos.

$\mathrm{Ci}$, porcentaje aprobado el Ayuntamiento según tablas.

Vs, valor del suelo en la fecha de la transmisión a efectos del impuesto sobre bienes inmuebles».

Teniendo en cuenta que el número máximo de años que contempla la LRHL es de 20 años y que, según la redacción original del art. 108.2 de la LRHL, el porcentaje máximo a aplicar por los Ayuntamientos era del 3 por 100, resulta que el incremento máximo podría alcanzar el 60 por 100 del valor del suelo en la fecha de la transmisión (cfr. J. LÓPEZ LEÓN, 2002, pág. 116).

9 Texto refundido de la Ley reguladora de las Haciendas Locales, aprobado por el RDL 3/2004, de 5 de marzo. 
Se trata, en suma, que interpretado en un sentido literal, la aplicación del sistema forfatario legal: (i) no garantiza se excluyan de gravamen transmisiones que no denuncien incrementos de valor; (ii) tampoco garantiza que aún denunciándose incremento de valor éste sea absorbido en su mayor parte por el impuesto; (iii) y, en todo caso, no se permite aportar prueba en contrario del incremento de valor calculado forfatariamente.

Pues bien, este problema de constitucionalidad ha permanecido latente hasta que explotó la crisis inmobiliaria de $2007^{10}$. Hasta este año la fórmula forfataria contemplada en la LRHL de 1988 tendía a dar un incremento de valor inferior o igual al real y, por tanto, los contribuyentes no la cuestionaban. Sin embargo a partir de este año la tendencia cambió radicalmente, dando lugar a numerosas situaciones en las que materialmente la transmisión del terreno no había dado lugar a un incremento de valor del terreno y, por ende, que el sistema forfatario previsto por el legislador para cuantificar el Impuesto de plusvalía estaba gravando plusvalías ficticias, irreales.

\section{NATURALEZA DEL SISTEMA CUANTIFICADOR DEL INCREMENTO DE VALOR}

\subsection{Esquema}

Estamos en que el sistema cuantificador derivado de la LRHL es de signo forfatario siendo susceptible de someter a gravamen plusvalías ficticias cosa que es susceptible de generar problemas de constitucionalidad.

Adviértase que la fórmula forfataria determinante del incremento del valor tiene un doble efecto: (i) Por un lado, afecta a la sujeción tributaria, de tal manera que si se determina que existe un incremento de valor se entenderá realizado el hecho imponible. (ii) Por otro lado, afecta a la cuantificación tributaria, de tal manera que el incremento de valor así determinado se erige en la base imponible del tributo.

En este marco caben tres opciones: elementales: (i) Considerar que se trata de una presunción iures et de iure o, más precisamente, de una ficción jurídica ${ }^{11}$, que no infringe la Constitución. (ii) Considerar que se trata de una presunción iuris tantum. (iii) Considerar que se trata de una presunción iures et de iure o, más precisamente, de una ficción jurídica, que sí infringe la Constitución.

\subsection{Ficción jurídica ajustada a la Constitución}

Según este criterio, el sistema cuantificador del incremento de valor contemplado por la LRHL consiste en:

(i) Por un lado, se trata de una ficción jurídica, pues no cabe que se aporte prueba en contrario ni por el contribuyente ni por la Administración y, además, se admite que pueda no haber correlación entre el hecho base y el presupuesto jurídico, pues lo que se pretende gravar no es el incremento real del valor sino el incremento legal.

(ii) Por otro lado, se trata de una ficción jurídica que no contraviene la Constitución.

Este criterio ha sido el seguido prácticamente sin excepción por los Ayuntamientos ${ }^{12}$ auspiciados por la doctrina administrativa de la Subdirección General de Tributos Locales ${ }^{13}$. Un sector de la doctrina científica

10 A destacar que la crisis económica iniciada en el 2007 es una de las causas que justifican las reformas fiscales de la vivienda propuestas por un significativo sector doctrinal (cfr. A. URQUIZU CAVALLÉ, 2018, pág. 915 y ss.; M. VILLCA POZO, 2018, pág. 889 y ss.)

11 Decimos que, antes de una presunción iuris et de iure, estamos ante una ficción jurídica porque, según explican A. DEL BLANCO y B. GARCíA, 2015, pág. 67, en la presunción iures et de iure «la Administración podría declarar correcta una liquidación llevada a cabo por un contribuyente que se ajustase de una manera más correcta a la realidad material que se atendiese al método legalmente establecido». Así mismo, «en las presunciones iures et de iure, una vez se cumpla el hecho base, existen muchas probabilidades de que se cumpla el hecho consecuencia». Nada de ésto ocurre en el caso que nos ocupa y, por ende, técnicamente estamos ante ficción jurídica.

Para ser incluso más precisos, se trata de una ficción jurídica en su modalidad de regla de valoración, en cuya virtud, explican J. LÓPEZ y J. VERA, 2018, pág. 82, «el legislador está fijando la cuantía por la que se debe computar los bienes que forman la base imponible, siendo indiferente que mediante un procedimiento contradictorio el obligado tributario pudiera, a través de una actividad probatoria, obtener un valor diferente; es decir, la regla de valoración no pretende facilitar la prueba de un hecho a través de otro distinto, ni puede ser destruida arguyendo que la presunción utilizada por el legislador es errónea». Sobre esta temática, de las normas de valoración como ficciones jurídicas, vid. E. ESEVERRI MARTíNEZ, 1995, págs. 45 a 120.

12 Así, por lo que respecta al Ayuntamiento de Barcelona, vid. Resolución del Consell Tributari de Barcelona, de 18 de junio de 2014, el cual parte de su Informe 76/2012 (en Tributos Locales, núm. 120, 2015, págs. 111 a 118).

${ }_{13}$ Cfr. Informe de esta Subdirección de 18 de diciembre de 2002, así como sus Consultas de 17 de mayo de 2013, 23 de enero de 2014, de 27 de enero de 2014, de 6 de febrero de 2014, de 20 de junio de 2014 (cits. por M. ALÍAS CANTÓN, 2017, págs. 14, 17 y 18) 
REALA. Nueva Época - N.o 11, Abril-Septiembre 2019 - ISSN: 1989-8975 - DOI: 10.24965/reala.v0i11.10579 - [Págs. 156-183]

Efectos de la declaración de inconstitucionalidad parcial del IIVTNU tras la sentencia interpretativa dictada por el tribunal supremo.. Joan Pagès i Galtés

también estuvo en esta línea ${ }^{14}$ que, por otra parte, y como veremos acto seguido, fue avalada por varias resoluciones judiciales.

Como era de esperar, tras la crisis económica del 2007 se empezaron a dar muchos casos en que el incremento de valor calculado de forma forfataria era muy superior al que se desprendía de los datos fácticos, cosa que propició el aumento de los recursos amparándose en los criterios expuestos por buena parte de la doctrina científica a la que más adelante aludiremos.

Si bien algunas resoluciones judiciales han fallado a favor de los Ayuntamientos, no aceptando el argumento de la falta o el menor incremento del valor real de los terrenos y desestimando anular las liquidaciones impugnadas ${ }^{15}$, la mayoría han considerado que estábamos ante una presunción iuris tantum.

\subsection{Presunción iuris tantum}

Según este criterio, el sistema cuantificador del incremento de valor contemplado por la LRHL consiste en una presunción iuris tantum, pues ésta es la única manera de salvar su constitucionalidad.

Como hemos apuntado, éste es el criterio sostenido por un importante sector de la doctrina científica ${ }^{16}$, al considerar que, aun cuando de una dicción literal de la LRHL se deduce que estamos ante una ficción jurídica contra la que no cabe prueba en contrario, ésto atentaría contra los más elementales principios constitucionales en la medida que se someterían a gravamen incrementos irreales. De ahí que sea preciso forzar la letra de la ley a los efectos de interpretar que estamos ante una mera presunción iuris tantum y, por ende, que el contribuyente puede probar la inexistencia de incremento o, en su caso, que el incremento real es menor al que se deriva del sistema cuantificador legal.

Y, como también hemos apuntado, es el criterio seguido por la mayoría de las resoluciones judiciales, cuestión distinta es el tipo de prueba que han reclamado. Lo ordinario es que el contribuyente haya aportado un informe pericial que no haya sido desvirtuado por la Administración ${ }^{17}$, aun cuando en algún caso se ha admitido como prueba suficiente la mera aportación de la escritura de compraventa donde consta que el precio de venta es inferior al de compra ${ }^{18}$,

Un supuesto curioso nos lo ofrece la Sentencia del JCA núm. 1 de Cuenca, de 27 de septiembre, ratificada por la STSJ de Castilla-La Mancha, de 17 de abril de 2017. Decimos que es un caso curioso porque admite la pretensión de un contribuyente en el sentido de que la base imponible del impuesto debe determinarse siguiendo un sistema de capitalización mediante el método matemático del descuento simple. Se trata, por tanto, de una estimación objetiva que se aparta del método contemplado por el legislador. Como advierte GARCÍA FRÍAS ${ }^{19}$, la aplicación de este sistema alternativo (denominado "fórmula de Cuenca»), «está siendo desestimada de forma prácticamente unánime por los tribunales».

En efecto, la postura mayoritaria de los órganos jurisdiccionales consiste en: (i) Considerar que la fórmula empleada por el legislador para calcular la base imponible tiene carácter de presunción iuris tantum. (ii) La

${ }_{14}$ Cfr. G. ORÓN MORATAL, 1992, 1992, pág. 117; E. ESEVERRI MARTíNEZ, 1993, pág. 137; L. M. ALONSO GONZÁLEZ, 1995, pág. 335.

15 C. CHECA GONZÁLEZ, 2000, pág. 369, cita en esta línea la STSJ de Andalucía -Granada- de 26 de enero de 1998, JT 1998/62, cuyo ponente fue E. ESEVERRI MARTíNEZ, quien trató de este tema en 1993, págs. 133 a 144. P. CHICO DE LA CÁMARA 2013, pág. 36, cita las SSTSJ de Andalucía de 5 de mayo de 1997 (JT 1997/566), de 26 de enero de 1998 (JT 1998/1957), de 4 de marzo de 2002 (JT 2002/474), de 10 de marzo de 2002 (JT 2003/910); STSJ de Canarias de 3 y 6 de septiembre de 2000. Por su parte, B. ANGLĖS JUANPERE, 2018, pág. 109, cita en esta línea la Sentencia del Juzgado de lo Contencioso-Administrativo (JCA) núm. 3 de Oviedo, de 20 de febrero de 2014 y la Sentencia del JCA núm. 2 de Barcelona, de 18 de abril de 2016.

16 J. I. RUBIO y S. ARNAL, 1989, págs. 386, 387 y 398; A. AGUNDÉZ FERNÁNDEZ, 1990, pág. 82; A. HERNÁNDEZ, 1991, pág. 83; F. CASANA MERINO, 1994, pág. 125; F. QUESADA SANTIUSTE, 2001, pág. 114; C. CHECA GONZÁLEZ, 2000, pág. 370; J. A. ŚÁNCHEZ GALIANA, 2002, pág. 125; B. MORENO SERRANO, 2012, pág. 176.

17 P. CHICO DE LA CÁMARA, 2013, pág. 37, cita la STSJ de Canarias de 12 de enero de 2001 (JT 2001/578); las SSTSJ de Castila-La Mancha de 3 de septiembre de 1999 (JT 1999/1783), de 17 de abril de 2012 (JUR 2012/58828); las SSTSJ de Catalunya de 9 de mayo y de 19 de septiembre de 2012, también la de 27 de septiembre de 2012 (JUR 2012/384172); la STSJ de Murcia de 6 de junio de 2001 (JUR 2001/238178); la Resolución del Tribunal Administrativo de Navarra, de 9 de agosto de 2011 (La Ley, núm. 2011/165497); las SSTSJ de Valencia de 26 de mayo de 1997 (JT 1997/679), de 24 de julio de 1998 (JT 1998/1161), de 29 de enero de 1999 (JT 1999/492), de 11 de abril de 2001 (JT 2001/1463), de 17 de septiembre de 2001 (JUR 2001/ 275905), de 24 y 29 de enero de 2003 (JT 2003/331 y 402), de 26 de marzo de 2003 (JUR 2003/245370). Entre otras muchas, destacaremos por su precisión la Sentencia del JCA núm. 1 de Tarragona, de 11 de mayo de 2015 (recurso núm. 269/2014) y la STSJ de Madrid de 15 de junio de 2016 (recurso núm. 1117/2015).

18 Así, M. ALÍAS CANTÓN, 2017, pág. 13, cita la STSJ de Valencia de 14 de septiembre de 2016 (recurso núm. 4/2016).

19 A. GARCÍA FRÍAS, 2017, pág. 33. 
carga de la prueba recae en el contribuyente. (iii) Una vez el contribuyente ha demostrado a juicio del órgano jurisdiccional que el incremento de valor calculado según la fórmula forfataria del legislador es inexistente o es inferior al real, lo que procede es, respectivamente, declarar la no sujeción al impuesto o tomar en consideración como base imponible el incremento de valor real que se ha probado.

A nuestro modo de ver, el criterio que hemos expuesto se ajusta perfectamente a la Constitución pues consiste en un apurar las posibilidad de interpretación que nos ofrece nuestro ordenamiento jurídico a les efectos de evitar la inconstitucionalidad de los preceptos legales que inmediatamente regulan la base imponible del impuesto y que de forma mediata conforman la sujeción al gravamen ${ }^{20}$. En la medida que esta interpretación admite la aportación de prueba por parte de los contribuyentes a los efectos de impedir que se sometan ope legis a gravamen incrementos de valor ficticios, ya se respetan los principios de capacidad, no confiscatoriedad e interdicción de la indefensión. Ciertamente, se plantea un problema de seguridad jurídica, pues no queda claro cuál es la forma de probar el importe del incremento real, pero la doctrina jurisprudencial puede cubrir esta laguna legal a través de la interpretación.

Sin embargo, esta postura no ha sido compartida por algunas resoluciones judiciales al entender que la literalidad de la ley es demasiado evidente para forzar una interpretación distinta a lo que dice, de tal manera que no se puede sostener que estamos ante una presunción iuris tantum, sino que estamos ante un ficción jurídica y que, como no se ajusta a los principios constitucionales, debe reputarse inconstitucional.

\subsection{Ficción jurídica no ajustada a la Constitución}

Según este criterio el sistema cuantificador del incremento de valor contemplado por la LRHL consiste en:

(i) Por un lado, negar que estemos ante una presunción iuris tantum. Antes al contrario, estamos ante una ficción jurídica, pues no cabe que se aporte prueba en contrario ni por el contribuyente ni por la Administración y, además, se admite que pueda no haber correlación entre el hecho base y el presupuesto jurídico, pues lo que se pretende gravar no es el incremento real del valor sino el incremento legal.

(ii) Por otro lado, se trata de una ficción jurídica que sí contraviene la Constitución, pues pugna abiertamente con determinados principios constitucionales.

Este criterio ha sido defendido por algunos autores ${ }^{21}$. El caso es que, al haber sido asumido por algunos órganos jurisdiccionales, se han promovido determinadas cuestiones de inconstitucionalidad que, en los términos que acto seguido expondremos, han provocado la inconstitucionalidad parcial de la normativa reguladora del impuesto.

\section{DECLARACIÓN DE INCONSTITUCIONALIDAD}

\subsection{Cuestiones de inconstitucionalidad}

En lo que al presente estudio afecta, las cuestiones de inconstitucionalidad promovidas por órganos jurisdiccionales pueden clasificarse como sigue:

\subsubsection{Base imponible calculada en función del valor catastral, el cual puede superar el valor de mercado}

Esta es la cuestión de inconstitucionalidad núm. 409/2016 promovida por el JCA núm. 22 de Madrid. Fue inadmitida por la STC 57/2017, de 11 de mayo, al considerar que si los valores catastrales estaban mal

${ }^{20}$ Así, como explica FERREIRO LAPATZA, 1989, pág. 31, «el Tribunal Constitucional ha señalado con suficiente nitidez (STC de 2 de febrero de 1.981) que es necesario "apurar las posibilidades de interpretación" de los preceptos "conforme a la Constitución" y declarar tan sólo la inconstitucionalidad de aquéllos cuya incompatibilidad con la misma resulte indudable por ser "imposible" el llevar a cabo tal interpretación; y que sólo procede declarar la inconstitucionalidad de una norma cuando "no puede" interpretarse de acuerdo con la Constitución por ser de un contenido "incompatible" con la misma (F. J. 1)».

${ }_{21}$ Como es el caso de R. FALCÓN y TELLA, 1993, pág. 32. Por su parte, J. E. VARONA ALABERN, 2010, pág. 12, plantea la inconstitucionalidad de la regulación del IIVTNU en base a la conculcación de los principios de seguridad jurídica y de capacidad económica. 
REALA. Nueva Época - N.o 11, Abril-Septiembre 2019 - ISSN: 1989-8975 - DOI: 10.24965/reala.v0i11.10579 - [Págs. 156-183]

Efectos de la declaración de inconstitucionalidad parcial del IIVTNU tras la sentencia interpretativa dictada por el tribunal supremo.. Joan Pagès i Galtés

determinados, ello no es un problema que afecte al principio de capacidad, pudiéndose resolver articulando los mecanismos de impugnación previstos en la normativa vigente contra estos valores.

\subsubsection{Se somete a tributación situaciones de inexistencia de incremento de valor. Encontramos cuatro cuestiones de inconstitucionalidad que cabe clasificar en estos dos grupos:}

\subsubsection{Desaparición sobrevenida de su objeto}

Esta es la cuestión de inconstitucionalidad núm. 232/2016 promovida por el JCA núm. 1 de Vitoria. La STC 48/2017, de 27 de abril, declara la extinción de la cuestión prejudicial de validez con relación a los artículos 4.1, 4.2.a) y 7.4 de la Norma Foral 46/1989, de 19 de julio, del IIVTNU de Álava, por desaparición sobrevenida de su objeto.

\subsubsection{Declaración de inconstitucionalidad}

En las cuestiones de inconstitucionalidad que ahora pasaremos a enumerar, el TC viene a declarar la inconstitucionalidad y nulidad de determinados preceptos reguladores del IIVTNU, en la medida que sometan a tributación situaciones de inexistencia de incremento de valor o situaciones inexpresivas de capacidad económica.

A) Normas Forales de Guipúzcoa y Álava

(i) En primer lugar, tenemos la cuestión de inconstitucionalidad núm. 1012/2015 promovida por el JCA núm. 3 de San Sebastián. La STC 26/2017, de 16 de febrero, la admite parcialmente en relación con los artículos 4.1, 4.2.a) y 7.4 de la Norma Foral 16/1989, del IIVTNU de Guipúzcoa.

(ii) En segundo lugar, tenemos la cuestión de inconstitucionalidad núm. 6444/2015 promovida por el JCA núm. 1 de Vitoria. La STC 37/2017, de 1 de marzo, sigue idéntico criterio al de la ya citada STC 26/2017 relativa a Guipúzcoa, pues la admite parcialmente en relación con los artículos 4.1, 4.2.a) y 7.4 de la Norma Foral 46/1989, de 19 de julio, del IIVTNU de Álava,

B) TR de la LRHL

En tercer lugar, tenemos las cuestiones de inconstitucionalidad núms. 4864,4865, 4866, 4867 y 4868/2016, promovidas por el JCA núm. 1 de Jerez. La STC 59/2017, de 11 de mayo ${ }^{22}$. La STC 59/2017, de 11 de mayo, partiendo de sus anteriores SSTC 26/2017 -Guipúzcoa- y 27/2017 -Álava-, la admite en relación con los artículos 107.1, 107.2.a) y 110.4 del TR de la LRHL.

\section{C) Norma foral de Navarra}

En cuarto lugar, tenemos la cuestión de inconstitucionalidad núm. 686/2017. La STC 72/2017, de 5 de junio ${ }^{23}$, partiendo de sus anteriores SSTC 26/2017 -Guipúzcoa-, 27/2017 -Álava- y 59/2017 -TR de la LRHL-, la admite en relación con los artículos 175.2, 175.3 y 178.4 de la Ley Foral 2/1995, de 10 de marzo, de Haciendas Locales de Navarra.

\subsection{Esquema de los aspectos más relevantes de la declaración de inconstitucionalidad}

Hasta la fecha, pues, el TC ha dictado cuatro Sentencias por las que se declara la inconstitucionalidad de determinados preceptos reguladores del IIVTNU.

Tres afectan a territorios forales: (i) STC 26/2017, de 16 de febrero -Guipúzcoa-; (ii) STC 27/2017, de 1 de marzo, -Álava-; y, (iii) STC 72/2017, de 5 de junio -Navarra-

Y una afecta al territorio común: STC 59/2017, de 11 de mayo -TR de la LRHL-

\footnotetext{
22 Publicada en el BOE de 15 de junio de 2017. Puede verse también en Tribulos Locales, núm. 130, 2017, págs. 33 a 41

${ }^{23}$ Publicada en el BOE de 15 de julio de 2017.
} 
REALA. Nueva Época - N.o 11, Abril-Septiembre 2019 - ISSN: 1989-8975 - DOI: 10.24965/reala.v0i11.10579 - [Págs. 156-183]

Efectos de la declaración de inconstitucionalidad parcial del IIVTNU tras la sentencia interpretativa dictada por el tribunal supremo... Joan Pagès i Galtés

Aun cuando presentan algún ligero matiz de redacción, entendemos que sustancialmente contemplan idéntica doctrina constitucional. Sus aspectos más relevantes pueden esquematizarse como sigue:

\section{a) Fundamentos jurídicos-base}

Los fundamentos jurídicos en los que se basa la declaración de inconstitucionalidad son:

(i) Se considera constitucional gravar la «riqueza real o potencial» pero, contrariamente, se considera inconstitucional gravar una «riqueza inexistente, virtual o ficticia».

(ii) De ahí que se considere constitucional la opción política del legislador de someter a tributación los incrementos de valor mediante un «sistema de cuantificación objetiva» de capacidades económicas potenciales, siempre y cuando ello no comporte gravar incrementos irreales o ficticios dado que se atentaría contra el principio de capacidad económica del artículo 31.1 CE.

(iii) «[...] de esta manera, al establecer el legislador la ficción de que ha tenido lugar un incremento de valor susceptible de gravamen al momento de toda transmisión de un terreno por el solo hecho de haberlo mantenido el titular en su patrimonio durante un intervalo temporal dado, soslayando aquellos supuestos en los que no se haya producido ese incremento, lejos de someter a tributación una capacidad económica susceptible de gravamen, les estaría haciendo tributar por una riqueza inexistente, en abierta contradicción con el principio de capacidad económica del citado art. 31.1 CE».

(iv) No es óbice a la declaración de inconstitucionalidad el hecho de que los Ayuntamientos adopten la «reducción catastral» o la «actualización, incluso a la baja de los valores catastrales» en el marco previsto por el legislador pues, amén de que estas medidas no tienen porqué adoptarse por los Ayuntamientos, resulta que aun cuando se adoptaran, caso de no existir incremento, tales medidas podrían minorar su importe, pero no lo evitarían.

\section{b) Alcance de la declaración de inconstitucionalidad}

El alcance de la declaración de inconstitucionalidad se centra en los siguientes criterios:

(i) Según el TC, en su configuración actual, el IIVTNU no es con carácter general inconstitucional. Lo es únicamente en aquellos supuestos en que se somete a tributación situaciones inexpresivas de capacidad, esto es, aquellas que no presentan incremento de valor al momento de la transmisión. De ahí que los artículos 107.1 y 107.2.a) del TR de la LRHL [así como los arts. 4.1 y 4.2.a) de las citadas Normas Forales de Guipúzcoa y de Álava, y los arts. 175.2 y 175.3 de la citada Norma Foral de Navarra], tan sólo sean inconstitucionales y nulos «únicamente en la medida en que se someten a tributación situaciones inexpresivas de capacidad económica».

(ii) Respecto al artículo 110.4 del TR de la LRHL (así como del art. 7.4 de las citadas Normas Forales de Guipúzcoa y de Álava, y del art. 178.4 de la citada Norma Foral de Navarra), tenemos que el TC los declara inconstitucionales y nulos, «al impedir que los sujetos pasivos puedan acreditar la existencia de una situación inexpresiva de capacidad económica».

(iii) La STC 59/2017, indica que los citados artículos 107.2 y 110.4 del TR de la LRHL están «expulsados del ordenamiento jurídico, ex origine» en los términos que se han indicado, es decir, en la medida que sometan a tributación situaciones inexpresivas de capacidad económica. Declaración ésta que las SSTC 26 y 37/1997 no hacen respecto a los preceptos paralelos de las Normas Forales de Guipúzcoa y de Álava. En cambio, la STC 72/2017, sí que la vuelve a contemplar respecto a los artículos 175.2, 175.3 y 178.4 de la Norma Foral de Navarra, al indicar que están «expulsados del ordenamiento jurídico, ex origine».

Dado el criterio de unidad de doctrina que se desprende del cuerpo constituido por el conjunto de las SSTC que declaran la inconstitucionalidad parcial del IIVTNU, entendemos que la declaración formal por la que se expulsan ex origine determinados preceptos reguladores del IIVTNU afecta a todos los declarados inconstitucionales, es decir, los artículos 107.1, 107.2 y 110.4 del TR de la LRHL, así como los preceptos paralelos de las Normas forales de Guipúzcoa, Álava y Navarra.

(iv) Respecto a estos artículos citados, el TC considera que «sólo corresponde al legislador, en su libertad de configuración normativa, a partir de la publicación de la Sentencia, llevar a cabo las modificaciones 
o adaptaciones pertinentes en el régimen legal del impuesto que permitan no someter a tributación las situaciones de inexistencia de incremento de valor de los terrenos de naturaleza urbana».

(v) Desde un punto de vista subjetivo, estamos con MARTíNEZ-CARRASCO ${ }^{24}$ cuando dice que la STC 59/2017 -TR de la LRHL- (aunque lo mismo, entendemos cabe decir de las SSTC 26, 37 y 72//2017 -Guipúzcoa, Álava y Navarra-) «tiene efectos erga omnes, esto es, la eficacia de la inconstitucionalidad declarada se extiende tanto para los contribuyentes que impugnaron el acto administrativo liquidatorio que les fue notificado, como también para el resto de sujetos pasivos. Por consiguiente, cualquier sujeto pasivo del impuesto municipal queda amparado, en principio, para beneficiarse de la declaración de inconstitucionalidad».

(vi) Desde un punto de vista temporal, el mismo autor sostiene que la STC «desarrolla efectos generales desde el mismo día de su publicación, pero sólo en la medida que los preceptos legales viciados someten a tributación situaciones de inexistencia de incremento de valor», precisando que «la eficacia en el tiempo de la declaración de inconstitucionalidad no es ilimitada. Así. con arreglo a la dispuesto en el art. 40.1 LOTC $^{25}$ no pueden revisarse situaciones en las que haya recaído sentencia firme con fuerza de cosa juzgada [...]».

\section{EFECTOS MATERIALES Y FORMALES DE LA DECLARACIÓN DE INCONSTITUCIONALIDAD. LA INTERPRETACIÓN DEL TS}

\subsection{Efectos materiales: La sujeción a gravamen de los incrementos de valor real}

\section{a) Premisa básica}

La premisa básica de la que parten las Sentencias del TC examinadas es que el IIVTNU, tal y como está configurado por el TR de la LRHL y por las Normas Forales impugnadas, es constitucional siempre y cuando no grave incrementos de valor irreales, ficticios. De ahí que tan sólo han sido declarados inconstitucionales aquellos preceptos que atentan contra esta premisa. Concretamente aquellos preceptos que legitiman el gravamen de incrementos irreales [arts. 107.1 y 107.2 a) TR de la LRHL] sin admitir prueba en contrario (art. 110.4 TR de la LRHL) ${ }^{26}$.

Ello, a nuestro modo de ver, implica que continúan estando sometidos a gravamen los incrementos de valor real.

El problema es que, en esta ocasión, el TC asume una interpretación estricta del principio de legalidad, rechazando hacer una interpretación correctiva de la ley para adecuarla a su doctrina constitucional, optando, contrariamente, por encomendar esta tarea al legislador.

\section{b) Principio de legalidad y negación de la interpretación correctiva de la ley}

Damos por descontado que la fijación de los elementos esenciales determinantes del mecanismo cuantificador de los impuestos municipales, cual es el caso del IVTNU, está sujeto a la reserva de ley del artículo 31.3 CE.

Aun cuando, en el caso que nos ocupa, entendemos que el TC perfectamente hubiera podido declarar la constitucionalidad de la normativa legal procurando una interpretación adecuada a los principios constitucionales, lo cierto es que ha optado en esta ocasión por declarar lisa y llanamente la inconstitucionalidad ${ }^{27}$. Se da además la circunstancia que en tanto en cuanto el legislador no modifique la ley a los efectos de adaptarla a la doctrina sentada por las citadas Sentencia del TC, los Ayuntamientos tienen el grave problema

24 J. M. MARTÍNEZ-CARRASCO PIGNATELLI, 2017, pág. 91.

${ }^{25}$ Ley orgánica 2/1979, de 3 de octubre.

26 Y preceptos paralelos de las Normas Forales de Guipúzcoa, Álava y Navarra.

27 Desde nuestro particular punto de vista, el problema de fondo se da en la posición errática en la que se ha venido situando el TC a la hora de emplear el criterio de la interpretación correctiva de la ley. Así, por citar un ejemplo que consideramos muy ilustrativo y esclarecedor, el TC (Sentencia 31/2010, de 28 de junio) utilizó ampliamente el criterio de la interpretación correctiva de la ley a la hora de enjuiciar el Estatuto de Autonomía de Catalunya de 2006, cuando, a nuestro modo de ver, ello resultaba a todas luces tan retorcido jurídicamente que ha generado problemas de toda índole; y, en cambio, el TC ha rechazado radicalmente la interpretación correctiva de la ley a la hora de enjuiciar la regulación legal del IIVTNU, cuando, según hemos indicado, se trata del criterio defendido por la mayoría doctrinal y jurisprudencial. 
REALA. Nueva Época - N.o 11, Abril-Septiembre 2019 - ISSN: 1989-8975 - DOI: 10.24965/reala.v0i11.10579 - [Págs. 156-183]

Efectos de la declaración de inconstitucionalidad parcial del IIVTNU tras la sentencia interpretativa dictada por el tribunal supremo... Joan Pagès i Galtés

consistente en que: (i) Están obligados a gestionar el tributo; (ii) a tales efectos están obligados a aplicar los preceptos legales reguladores del IIVTNU siempre y cuando se adecuen a la doctrina sentada por el TC; (iii) sin embargo, como que el TC exige que esta adecuación venga impuesta por una reforma legal, tenemos que en ausencia de cobertura legislativa la adecuación no puede derivar de una Ordenanza fiscal y, ni que decir tiene, de una práctica gestora municipal.

\subsection{Efectos formales: La gestión del impuesto en el interín de la declaración de inconstitucionalidad y la reforma del TR de la LRHL}

\section{a) La obligación administrativa de gestionar el impuesto}

Como, partiendo de doctrina precedente, se explica por NIETO MONTERO ${ }^{28}$ que la gestión tributaria es una función administrativa constituida por las potestades integradas por «poderes-deberes» destinadas a dar efectividad los créditos tributarios, «viniendo dicha expresión a significar que la Administración no sólo puede actuar, sino que viene obligada a hacerlo, de cara a la consecución de ese fin al que las potestades, enmarcadas dentro de una función administrativa, se orientan».

De tal manera, pues, que los Ayuntamientos que han establecido el IIVTNU no pueden negarse a gestionarlo en la medida que no ha sido derogado por el legislador y que el TC no lo impide.

El problema es cómo deben actuar los Ayuntamientos en su función gestora para discriminar los supuestos de inconstitucionalidad (aquellos donde se grava un incremento de valor irreal) de los supuestos de constitucionalidad (aquellos donde sí se grava de forma ponderada un incremento de valor real).

\section{b) Normas Forales de Guipúzcoa y de Álava de adaptación a la doctrina del TC}

Pues bien, en los casos de los territorios forales afectados por las SSTC 26 y 37/2017 -Guipúzcoa y Álava- los órganos legislativos competentes se han afanado por dar rápida respuesta al mandato del TC dictándose el Decreto Foral-Norma de Guipúzcoa 2/2017, de 28 de marzo ${ }^{29}$ y el Decreto Normativo de Urgencia Fiscal de Álava 3/2017, de 28 de marzo ${ }^{30}$ destinados a acomodar su respectiva normativa del IIVTNU a la doctrina del TC.

Esencialmente ambas establecen que la base imponible (incremento de valor) vendrá determinada por la diferencia entre los valores final e inicial calculados de conformidad con el Impuesto sobre Transmisiones Patrimoniales -caso de transmisiones onerosas- o del Impuesto sobre Sucesiones y Donaciones -caso de transmisiones lucrativas-. Además, se establece que las modificaciones introducidas no tienen carácter retroactivo sobre los devengos anteriores a la fecha de publicación de las respectivas Sentencias del TC, y que no son aplicables a los actos que hayan adquirido firmeza con anterioridad a tal fecha.

Ciertamente, puede discreparse del contenido de estas normas forales equivalentes al Decreto-ley ${ }^{31}$ pero, aún que así fuera, debe reconocerse que han dado una rápida respuesta capaz de dotar de seguridad jurídica a los Ayuntamientos y a los sujetos pasivos.

\section{c) Norma Foral de Vizcaya de adaptación a la doctrina del TC}

También ha actuado con cierta rapidez el territorio foral de Bizcaia, pues a pesar de que su normativa sobre el IIVTNU no estaba afectada por ninguna declaración de inconstitucionalidad, se ha dictado el Decreto Foral Normativo 3/2017, de 20 de junio, por el que se modifica la Norma Foral 8/1989, de 30 de junio, sobre el Incremento de Valor de los Terrenos de Naturaleza Urbana ${ }^{32}$.

Esencialmente viene a establecer que la base imponible (incremento de valor) vendrá determinada por la diferencia entre los valores final e inicial que consten en los documentos acreditativos de los títulos de propiedad o de constitución o transmisión de derechos reales de goce limitativos del dominio, sin perjuicio de que puedan ser objeto de comprobación de valores. Además, se establece que las modificaciones introducidas no tienen

\footnotetext{
28 J. J. NIETO MONTERO, 1997, pág. 29.

29 BO de Guipúzcoa, de 31 de marzo de 2017.

30 BO de Álava, de 5 de abril de 2017.

31 Vid. las críticas que realiza S. ARANA LANDíN, 2018, págs. 89 a 105, respecto al Decreto Foral Norma de Guipúzcoa $2 / 2017$.

32 BO de Bizkaia, de 22 de junio de 2017.
} 
REALA. Nueva Época - N.o 11, Abril-Septiembre 2019 - ISSN: 1989-8975 - DOI: 10.24965/reala.v0i11.10579 - [Págs. 156-183]

Efectos de la declaración de inconstitucionalidad parcial del IIVTNU tras la sentencia interpretativa dictada por el tribunal supremo.. Joan Pagès i Galtés

carácter retroactivo sobre los devengos anteriores a la entrada en vigor del Decreto Foral Normativo, es decir, el 22 de junio de 2017, y que no son aplicables a los actos que hayan adquirido firmeza con anterioridad a tal fecha.

\section{d) Ley Foral de Navarra de adaptación a la doctrina del TC}

Y, en fin, también ha actuado con cierta rapidez el territorio foral de Navarra, pues una vez dictada la STC 72/2017, de 5 de junio, por la que se declara la inconstitucionalidad parcial del IIVTNU regulado en la Ley Foral 2/1995, de 10 de marzo, de Haciendas Locales de Navarra, se ha dictado la Ley Foral 19/2017, de 27 de diciembre, por la que se modifica esta Ley Foral $2 / 1995^{33}$.

Esencialmente viene a establecer que la base imponible (incremento de valor) vendrá determinada por la diferencia entre los valores final e inicial que consten en los títulos de transmisión y de adquisición (caso de transmisión onerosa) o el que conste a efectos del Impuesto sobre Sucesiones y Donaciones (caso de transmisión lucrativa), sin perjuicio de que puedan ser objeto de comprobación de valores. Además, se establece que las modificaciones introducidas no tienen carácter retroactivo sobre los devengos anteriores a la fecha de publicación de la STC 72/2017, es decir, el 15 de julio de 2017, y que no son aplicables a los actos que hayan adquirido firmeza con anterioridad a tal fecha.

\section{e) Ausencia de reforma del TR de la LRHL para adaptarlo a la doctrina del TC}

Como bien advirtió RUBIO DE URQUÍA ${ }^{34}$, tras las SSTC 26 y 37/2017 -Guipúzcoa y Álava-, el TC ya se pronunció sobre la plusvalía municipal y, por tanto, «ahora toca que se pronuncie el legislador». Hemos visto que así lo han hecho los órganos legislativos de los territorios forales pero, lamentablemente, no ha sido el camino seguido por el legislador estatal, pues a fecha de hoy tan sólo encontramos una proposición de ley de reforma del TR de la LRHL publicada el 9 de marzo de $2018^{35}$ a pesar de que la STC 59/2017 sobre esta ley estatal se dictó el 11 de mayo de 2017.

Esto deja tanto a los Ayuntamientos como a los sujetos pasivos en una situación de extrema inseguridad jurídica que tan sólo en parte se ha solventado tras los criterios interpretativos fijados por el Tribunal Supremo respecto a la declaración de inconstitucionalidad contenida en la STC 59/2017.

\subsection{Criterios interpretativos fijados por la STS sobre la declaración de inconstitucionalidad del IIVTNU}

En efecto, la STS de 9 de julio de 2018, recaída en casación ${ }^{36}$, advierte que la doctrina del TC sobre la declaración parcial de incostitucionalidad del IIVTNU ha provocado que: (i) Mientras por algunos órganos judiciales se interprete que los Ayuntamientos están legitimados para exigir el impuesto salvo cuando se acredite que no media incremento real de valor $y$, por ende, procede considerar legítimas las liquidaciones que se giren en las transmisiones que denuncien un incremento de valor real ${ }^{37}$; (ii) otros órganos judiciales sostienen que, en tanto en cuanto el legislador no adecúe el impuesto a la doctrina del TC, los Ayuntamientos no pueden en ningún caso exigir el impuesto y, por ende, procede anular sistemáticamente las liquidaciones que se giren ${ }^{38}$.

33 BO de Navarra, de 30 de diciembe de 2017.

34 J. I RUBIO DE URQUÍA, 2017, pág. 7.

35 Nos referimos a la Proposición de ley 122/000196, presentada por el Grupo Parlamentario Popular en el Congreso (BO de las Cortes Generales-Congreso de los Diputados, de 9 de marzo de 2018; vid. también El Consultor, núm. 3, 2018, smarteca, págs. 1 a 5; Tributos Locales, núm. 134, 2018, págs. 116 a 120). Para J. I. RUBIO DE URQUÍA, 2018, pág. 8, «Es curioso que la iniciativa de reforma no partiera en su día del Gobierno de la Nación mediante la aprobación de un Decreto-Ley, que habría estado perfectamente justificado, que no haya partido ahora de la misma institución mediante la remisión a las Cortes de un Proyecto de Ley, que habría sido lo propio, y que tal iniciativa la haya tomado, según lo dicho, el Grupo Parlamentario Popular del Congreso mediante la Proposición de Ley de referencia». Además, el mismo autor critica que en la citada Proposición de ley no se regula asazmente su dimensión temporal, cabiendo preguntarse "¿qué sucede con los devengos del impuesto producidos hasta la referida entrada en vigor de la Ley?».

36 Sentencia núm. 1163/2018 (núm. de procedimiento 6226/2017).

37 Ésta es precisamente la postura de la STSJ de Aragón, de 27 de septiembre de 2017 (rec. núm. 174/2016), que es objeto de casación en la STS que nos ocupa.

${ }^{38}$ En el FD tercero de la STS que nos ocupa se cita en este sentido la postura mantenida por la STSJ de Madrid, de 19 de julio de 2017 (rec. núm. 783/2016), seguida por Sentencias dictadas por otros TSJ como los de Castilla y León -Burgos-, Galicia, Catalunya o Navarra. 
REALA. Nueva Época - N.o 11, Abril-Septiembre 2019 - ISSN: 1989-8975 - DOI: 10.24965/reala.v0i11.10579 - [Págs. 156-183]

Efectos de la declaración de inconstitucionalidad parcial del IIVTNU tras la sentencia interpretativa dictada por el tribunal supremo...

La STS que nos ocupa, se decanta decididamente por la primera postura citada viniendo a fijar la siguiente doctrina:

(i) Respecto a los artículos 107.1 i 107.2 del TR de la LRHL, interpreta que para la STC 59/2017 tan sólo adolecen de «una inconstitucionalidad y nulidad "parcial"». Por tanto, "son constitucionales y resultan, pues, plenamente aplicable, en todos aquellos supuestos en los que el obligado tributario no ha logrado acreditar, por cualquiera de los medios que hemos expresado en el fundamento de derecho Quinto, que la transmisión de la propiedad de los terrenos por cualquier título (o la constitución o transmisión de cualquier derecho real de goce, limitativo del dominio, sobre los referidos terrenos), no ha puesto de manifiesto un incremento de su valor o, lo que es igual, una capacidad económica susceptible de ser gravada con fundamento en el artículo $31.1 \mathrm{CE}$ ».

(ii) Respecto al artículo 110.4 del TR de la LRHL, interpreta que para la a STC 59/2017 «es inconstitucional y nulo "en todo caso" (inconstitucionalidad total)», lo cual «posibilita que los obligados tributarios puedan probar, desde la STC 59/2017, la inexistencia de un aumento del valor de los terrenos ante la Administración municipal o, en su caso, ante el órgano judicial, y, en caso contrario, es la que habilita la plena aplicación de los artículos 107.1 y 107.2 del TRLHL».

A nuestro juicio, se trata de unos criterios interpretativos acertados, pues se ajustan a los principios rectores susceptibles de traer a colación.

\subsection{Principios rectores de la STS sobre la declaración de inconstitucionalidad del IIVTNU}

\section{a) Principios rectores que sustentan la STS sobre la declaración de inconstitucionalidad del IIVTNU}

Desde nuestro punto de vista, los criterios interpretativos de la STS sobre la declaración de inconstitucionalidad del IIVTNU se sustenta sobre unos principios rectores que son fácilmente identificables y que deben iluminar la función gestora municipal en el interín de la declaración de inconstitucionalidad efectuada por la STC 59/2017 y la futura modificación del TR de la LRHL por parte del legislador:

1. Principio de capacidad económica. Se trata del principio básico de contribución contemplado por el artículo $31.1 \mathrm{CE}$ y que sustenta la declaración de inconstitucionalidad efectuada por las SSTC respecto al gravamen de riqueza inexistente. Y así, la STS considera que no son susceptibles de estar gravados los supuestos en los que no se ha puesto de manifiesto un incremento de valor del terreno, o lo que es igual, una capacidad económica susceptible de ser gravada con fundamento en el artículo 31.3 CE.

2. Principios de legalidad y de preferencia de ley en el marco de la doctrina del TC. De acuerdo con los artículos 9.3, 31.3 y $164 \mathrm{CE}$, en tanto en cuanto no haya mediado declaración de inconstitucionalidad, el Ayuntamiento ha de ajustarse a lo dispuesto por el legislador. Y así, la STS de 9 de julio de 2018, considera la constitucionalidad parcial de los artículos 107.1 y 107.2.a) del TR de la LRHL, lo cual implica la aplicación de las reglas reguladoras de la base imponible.

3. Principio de contribución a los gastos públicos. Según el artículo 31.1 CE la contribución al sostenimiento de los gastos públicos es un deber. De ahí que, para canalizar este deber de los contribuyentes, también sea un deber el ejercicio de la función administrativa de gestionar los tributos legalmente establecidos. Y así, la STS de 9 de julio de 2018, admite la exacción del tributo en la medida que la transmisión denuncie un incremento de valor del terreno.

4. Principio de salvaguarda de los derechos y garantías de los obligados tributarios en la gestión tributaria. Según el artículo 3.2 de la LGT, «La aplicación del sistema tributario se basará en la proporcionalidad, eficacia y limitación de costes indirectos derivados del cumplimiento de obligaciones formales y asegurará el respeto de los derechos y garantías de los obligados tributarios». Y así, la STS de 9 de julio de 2018, interpreta la inconstitucionalidad total del artículo 110.4 del TR de la LRHL, en la medida que impide a los sujetos pasivos acreditar la existencia de una situación inexpresiva de capacidad económica, permitiéndoles servirse de cualquier medio de prueba admisible en derecho.

Destacamos que la STS interpreta que ha de ser el obligado tributario quien demuestre que la transmisión no denuncia incremento de valor. Se trata del mismo criterio utilizado por el Decreto foral-norma 
REALA. Nueva Época - N.o 11, Abril-Septiembre 2019 - ISSN: 1989-8975 - DOI: 10.24965/reala.v0i11.10579 - [Págs. 156-183]

Efectos de la declaración de inconstitucionalidad parcial del IIVTNU tras la sentencia interpretativa dictada por el tribunal supremo.. Joan Pagès i Galtés

2/2017, de Guipúzcoa, y que ha sido criticado por ARANA LANDÍN ${ }^{39}$ al entender que da lugar a un supuesto de no sujeción singular, pues si no hay incremento de valor tampoco hay sujeción al impuesto y, por ende, lo lógico sería que fuera la Administración sobre quien recayera la carga de probar la existencia de incremento de valor como elemento constitutivo de la sujeción. Al no hacerse así, haciendo recaer en el sujeto pasivo la carga de probar la inexistencia de incremento de valor para que sea declarada la no sujeción, la citada autora entiende que se está utilizando anómalamente para la sujeción una técnica que es propia de las exenciones.

A nuestro modo de ver, aun cuando sea cierto que nuestro ordenamiento jurídico parte del principio consistente en que la carga de la prueba de la realización del hecho imponible recae en la Administración ${ }^{40}$, de tal manera que resulta anómalo que sea el contribuyente quien haya de demostrar que no está sujeto a gravamen; no es menos cierto que este principio puede ceder cuando concurran circunstancias excepcionales, tal y como acontece en el IIVTNU, donde se da la circunstancia que en toda transmisión media la presunción hominis ${ }^{41}$ de que en la normalidad de los casos se denunciará un incremento de valor, siendo que por aplicación del principio de facilidad probatoria debe considerarse proporcional exigir que sea el contribuyente quien destruya semejante presunción.

5. Principios de seguridad jurídica e interdicción de la arbitrariedad. El artículo 9.3 CE establece los principios de seguridad y de interdicción de la arbitrariedad de los poderes públicos. Y así, la STS de 9 de julio de 2018, fija una doctrina interpretativa que evita disparidad de criterios. En este sentido ya había sido útil la aprobación por parte de los órganos municipales de los criterios a seguir tras la STC 59/201742.

Insistimos en que, siempre según nuestro parecer, estos son los principios rectores en base a los cuales se debe cubrir la laguna creada por la declaración de inconstitucionalidad en tanto el legislador no se decida a modificar el TR de la LRHL. Con este fin, pasaremos a examinar la actuación a seguir por los órganos gestores y los medios de defensa a utilizar por los obligados tributarios, diferenciando entre las transmisiones realizadas después de la declaración de inconstitucionalidad y las realizadas con anterioridad. Pero, con carácter previo, antes conviene practicar algunas consideraciones sobre los principios que son ignorados por la STS que nos ocupa.

\section{b) Principios rectores ignorados por la STS sobre la declaración de inconstitucionalidad del IIVTNU}

En efecto, se da la circunstancia que, a raíz del objeto del recurso de casación, la STS de 9 de julio de 2018 no fija doctrina interpretativa sobre tres principios que también consideremos de máxima relevancia.

1. El principio de interdicción de la confiscatoriedad. Se trata de un principio contemplado para el sistema tributario por el artículo 31.3 CE. En base al mismo creemos debe darse respuesta a los supuestos en que, si bien el incremento de valor existe, la aplicación del tributo puede absorber en exceso la capacidad económica gravada.

2. El principio de retroactividad de las declaraciones de nulidad. Se trata de un principio que se deduce del artículo 40.1 de la LOTC, y que entendemos se corrobora por la STC 59/2017 cuando indica que los artículos 107.2 y 110.4 del TR de la LRHL están «expulsados del ordenamiento jurídico, ex origine». En base al mismo creemos debe darse respuesta a los supuestos de ingresos derivados de actos firmes en vía administrativa efectuados con anterioridad a la publicación de la STC que declara la inconstitucionalidad parcial del IIVTNU.

3. Los principio de responsabilidad patrimonial y suficiencia financiera de las entidades locales. El artículo 106.2 CE establece el derecho de los particulares a reclamar en el marco legal la responsabilidad patrimonial de los entes públicos por el funcionamiento de los servicios públicos. El artículo 142 CE establece que las Haciendas locales deberán disponer de los medios suficientes para el desempeño de sus funciones. En base al mismo creemos debe darse respuesta a los supuestos de ingresos confirmados por sentencia

39 S. ARANA LANDÍN, 2018, págs. 92 a 94.

40 Así se deduce del art. 105.1 LGT.

${ }^{41}$ A ellas se referie el art. 108.2 LGT.

42 Esto es lo que ha hecho el Ayuntamiento de Barcelona cuando su Consell Tributari ha emitido el Informe aprobado el 13 de julio de 2017 (expediente 216/2017), donde se fija de forma detallada la línia de actuación. En similar sentido, aunque con un contenido mucho más escueto, también encontramos la moción aprobada en fecha de 25 de julio de 2017 por el Pleno del Ayuntamiento de L'Hospitalet de Llobregat. 
REALA. Nueva Época - N.o 11, Abril-Septiembre 2019 - ISSN: 1989-8975 - DOI: 10.24965/reala.v0i11.10579 - [Págs. 156-183]

Efectos de la declaración de inconstitucionalidad parcial del IIVTNU tras la sentencia interpretativa dictada por el tribunal supremo.. Joan Pagès i Galtés

judicial firme así como los perjuicios económicos que genere para los Ayuntamientos la declaración de inconstitucionalidad.

Pasemos a tratarlos empezando por la relación que observa el principio de interdicción de la confiscatoriedad con los incrementos de valor escasos.

\section{INCREMENTOS DE VALOR INEXISTENTES VERSUS INCREMENTOS DE VALOR ESCASOS}

\subsection{Incrementos de valor inexistentes. Principio de capacidad económica}

Las SSTC analizadas, se centran en declarar la inconstitucionalidad del Impuesto en los supuestos de inexistencia de incremento de valor. Se trata, por tanto, de los supuestos más extremos donde, tras acreditarse que no media incremento de valor, tampoco existe capacidad alguna susceptible de imposición y, por tanto deben entenderse excluidos de gravamen siendo calificados como supuestos de no sujeción al IIVTNU.

Ni que decir tiene, este criterio es asumido plenamente por la STS de 9 de julio de 2018 (cfr. FJ séptimo. $\left.1 .{ }^{\circ}\right)$

\subsection{Incrementos de valor existentes pero escasos. Principio de interdicción de la confiscatoriedad}

Estamos en que las SSTC sobre la inconstitucionalidad parcial del IIVTNU, literalmente interpretada por la STS de 9 de julio de 2018, declaran la inconstitucionalidad del Impuesto en los supuestos de inexistencia de incremento de valor, pues está claro que aquí no media capacidad económica alguna que gravar. Ahora bien, la doctrina constitucional sobre el IIVTNU no se pronuncia sobre los supuestos de plusvalías escasas, esto es, de los supuestos en que, si bien el incremento de valor existe, la aplicación del tributo puede absorber en exceso la capacidad económica gravada. De ahí que sea necesario interpretar la doctrina constitucional para resolver esta cuestión. Sin embargo, la STS de 9 de julio de 2018 tampoco se pronuncie sobre este tema aduciendo en su FD Quinto que «[...] no se nos ha planteado aún y tampoco ha sido resuelto por el Tribunal Constitucional en la STC 59/2017».

Huelga decir que se trata de un problema nada despreciable que ya ha sido planteado por la doctrina científica, como es el caso de MARTíN QUERALTT ${ }^{43}$, quien nos alerta de que "[..] no vaya a ser que se repute inconstitucional el gravamen de una minusvalía de 100 euros y se acepte como constitucional el gravamen de una plusvalía que realmente ha sido de 100 euros y ha sido cuantificada en 10.000 euros». El mismo autor ya deja constancia que el TC hace hincapié «[...] entre la capacidad económica como "fundamento" de la tributación ("de acuerdo con") y la capacidad económica como "medida" del tributo ("en función de"), (Vid. especialmente las SSTC 71/2014, de 6 de mayo FJ 3 y 60/2015, de 18 de marzo, FJ 4)».

De acuerdo con este criterio, a nuestro modo de ver, si el principio de capacidad económica ha llevado al TC a impedir el gravamen por IIVTNU de las transmisiones que no denuncian incremento de valor del terreno, el principio de interdicción de la confiscatoriedad -íntimamente unido al de capacidad- debería llevar a impedir que se graven en exceso (absorbiendo la capacidad económica gravada) las transmisiones que sí denuncian incremento de valor del terreno. Lo cual implica: (i) Por un lado, que el sujeto pasivo tenga derecho a probar que el incremento de valor es inferior al que se desprende de los criterios forfatarios actualmente contemplados por el TR de la $\mathrm{LRHL}^{44}$. (ii) Por otro lado, que la normativa que el legislador dicte para adecuar la normativa del IIVTNU a la doctrina constitucional respete el principio de proporcionalidad y, por supuesto, no dé lugar al error de salto consistente en que a un incremento de valor real le pueda corresponder una cuota igual o superior al mismo ${ }^{45}$.

43 J. MARTíN QUERALT, 2017, 11. En la misma línea vid. C. PALAO TABOADA, 2017, pág. 22.

44 En este sentido, P. CUBILES SÁNCHEZ-POBRE, 2017, pág. 121, entiende que «[...] el principio de capacidad económica establecido en el artículo 31 de la Constitución española debiera suponer que nadie pudiera ser obligado a contribuir por un incremento de valor superior al verdaderamente experimentado». Semejante criterio es defendido por F. CASANA MERINO, 2017b, pág. 159.

${ }_{45}$ Como, según explica S. ARANA LANDíN, 2018, págs. 99 y 100, es susceptible de acontecer con el Decreto Foral Norma 2/2017, de 28 de marzo, de Guipúzcoa, por el que se pretende adaptar la Norma Foral 16/1989, a la STC 26/2017. Y así, la citada autora dice que caben «[...] casos en que un solo céntimo da lugar al nacimento de la obligación tributaria y, por tanto, a la aplicacón de la referida norma que, en valores de una ciudad como San Sebastián, tranquilamente puede dar lugar a una cuota del IIVTNU de 200.000 euros». En la misma línea, tendente a la necesidad de corregir semejante error de salto, vid. D. MARíN BARNUEVO-FABO, 2017, págs. 40 y 41; A. BARRIO GALLARDO, 2018, pág. 10. 


\section{TRANSMISIONES REALIZADAS TRAS LA DECLARACIÓN DE INCONSTITUCIONALIDAD}

\subsection{Plena eficacia temporal de la declaración de inconstitucionalidad}

Se ha discutido mucho sobre la eficacia temporal de sentencias por la que se declara la inconstitucionalidad de una norma, pero la discusión se centra en la eficacia retroactiva, pues no se discute que la declaración de inconstitucionalidad tiene efectos vinculantes generales a todos los poderes públicos tras la publicación oficial de la sentencia ${ }^{46} \mathrm{y}$, por ende, afecta plenamente a todos los actos susceptibles de gravamen realizados a partir de tal publicación.

En el caso que nos ocupa, tenemos que la STC 59/2017 sobre el TR de la LRHL se publicó en el BOE de 15 de mayo de 2017, lo cual implica que, sin lugar a dudas, alcanzará a todas las transmisiones (o la constitución o transmisión de cualquier derecho real de goce, limitativo de la propiedad, sobre los terrenos) producidos a partir de este fecha.

\subsection{Actuaciones a seguir por la Administración municipal}

\section{a) Planteamiento}

De acuerdo con la STS de 9 de julio de 2018, creemos pacífico sostener que: (i) Tras la publicación, en el BOE de 15 de mayo de 2017, de la STC 59/2017 sobre el TR de la LRHL, los Ayuntamientos de régimen común que tengan establecido el IIVTNU no pueden pretender someter a gravamen las transmisiones de terrenos que no denuncien incremento de valor real, mientras que sí pueden e incluso deben procurar el sometimiento a gravamen de las transmisiones de terrenos que denuncien incremento de valor real. (ii) También creemos pacífico sostener, porque igualmente asé se desprende de la referida STC, que corresponde al legislador determinar el sistema cuantificador del incremento real sometido a gravamen. (iii) Y, finalmente, aunque no se diga de forma explícita por la STC 59/2017 ni se pronuncie al respecto la STS de 9 de julio de 2018, entendemos que deben reputarse igualmente inconstitucionales los supuestos en que, si bien el incremento de valor existe, la aplicación del tributo puede absorber en exceso la capacidad económica gravada.

En este marco, la opción municipal que estimamos más ajustada a derecho por atender a los principios rectores enunciados en el subapartado 4.4 es la de no exigir de forma inmediata el cobro del impuesto si concurre alguna duda de que no hay incremento real de valor. Ahora bien, en la medida de que por falta de concreción legal el Ayuntamiento no pueda estar seguro de este hecho, también estimamos como más ajustado a derecho que el Ayuntamiento deba preservar su potestad-derecho a cobrar lo no pagado por el impuesto, como correlativo a la potestad-deber del Ayuntamiento a la devolución de lo eventualmente pagado por el impuesto. Este es el criterio que creemos viene a ratificarse por la STS de 9 de julio de 2018, interpretativa de la doctrina del TC.

Se trata, en suma, de que: (i) Si el Ayuntamiento no cobra el impuesto porque existe una duda de que no ha mediado incremento de valor, debe procurar se garantice que en el supuesto de que finalmente se acredite ha existido el incremento, se pueda exigir el pago. (ii) De esta forma, se compensa jurídicamente la garantía relativa al supuesto inverso consistente en que si el Ayuntamiento cobra el impuesto porque todo indica que ha mediado un incremento de valor, deberá procederse a la devolución de lo pagado si finalmente se acredita que no ha existido el incremento.

De aceptarse este criterio, entendemos que el instituto jurídico en cuya virtud mejor se puede canalizar es el de la suspensión del procedimiento.

\section{b) Suspensión del procedimiento}

Siguiendo el Informe del Consell Tributari del Ayuntamiento de Barcelona, de 13 de julio de 2017 (expediente 216/2017), entendemos que por parte de la Administración municipal gestora procede aplicar la medida cautelar contemplada en el artículo 56.3.i) de la Ley 39/2015, de 1 de octubre, de Procedimiento Ad-

46 Así, partiendo del art. 164.1 CE, el art. 38.1 LOTC establece: «Las sentencias recaídas en procedimientos de inconstitucionalidad tendrán el valor de cosa juzgada, vincularán a todos los Poderes Públicos y producirán efectos generales desde la fecha de su publicación en el "Boletín Oficial del Estado"». 
REALA. Nueva Época - N.o 11, Abril-Septiembre 2019 - ISSN: 1989-8975 - DOI: 10.24965/reala.v0i11.10579 - [Págs. 156-183]

Efectos de la declaración de inconstitucionalidad parcial del IIVTNU tras la sentencia interpretativa dictada por el tribunal supremo..

ministrativo Común de las Administraciones Públicas (LPAC), aplicable supletoriamente al ámbito tributario en virtud del artículo 7.2 de la LGT.

Este precepto de la LPAC atribuye a las Administraciones públicas la facultad de adoptar cualesquiera de las medidas que sean necesarias para asegurar la efectividad de la resolución. Dado el carácter abierto de este precepto legal, cabe interpretar que incluye la suspensión del procedimiento.

Si tenemos en cuenta que el caso ahora examinado estriba en que al órgano gestor le pueden asistir serias dudas sobre la realización del hecho imponible a raíz de que el legislador se retrasa en la adecuación de la ley a la doctrina del TC y que la Sentencia interpretativa del TS de 9 de julio de 2018 simplemente legitima el cobro del tributo cuando no se acredite por el sujeto pasivo inexistencia de incremento de valor, se comprenderá que estimemos como postura más ajustada a derecho que se adopte la suspensión del procedimiento a modo de medida cautelar ${ }^{47}$.

Al respecto debe distinguirse según estemos ante el sistema de autoliquidación o de liquidación.

I. Sistema de autoliquidación. (i) Si, como es lo más habitual, el Ayuntamiento ha establecido el sistema de autoliquidación al amparo del artículo 110.4 del TR de la LRHL, deberá continuar reclamando a los eventuales sujetos pasivos que presenten la correspondiente autoliquidación tal y como se venía haciendo antes de la declaración de inconstitucionalidad. (ii) La diferencia estriba en que tras la declaración de inconstitucionalidad debe discriminarse según existan indicios de que la transmisión denuncie o no un incremento real de valor y, caso de respuesta afirmativa, de si existen indicios de que el incremento real es inferior o no al derivado del sistema forfatario legal. (iii) A tales efectos, lo que estimamos más respetuoso a los derechos de los obligados tributarios, es que se les envíe una notificación indicándoles que no estarán sujetos al impuesto si presentan alguna prueba indiciaria de que la transmisión no denuncia incremento de valor real, o que se les liquidará por un importe inferior si demuestran que el incremento de valor real es inferior al que deriva de la aplicación del sistema forfatario legal. (iv) Si los obligados tributarios no presentan ningún indicio probatorio destinado a acreditar que su transmisión no denuncia incremento patrimonial o que el incremento real es inferior al forfatario derivado de la ley, entendemos que el Ayuntamiento está legitimado para exigir el impuesto en los términos previstos por la vigente normativa legal, incluso por vía de apremio. (v) Ahora bien, si los obligados tributarios sí presentan algún indicio probatorio destinado a acreditar que su transmisión no denuncia incremento patrimonial, entendemos que el Ayuntamiento debe proceder de oficio a la suspensión del procedimiento. (v) Mientras que si los indicios que presentan los obligados tributarios es para poner de manifiesto que el incremento de valor real es inferior al que deriva de la aplicación del sistema forfatario legal, entendemos que el Ayuntamiento debe proceder a dictar liquidación del impuesto tomando como base imponible este valor real.

II. Sistema de liquidación. (i) Si el Ayuntamiento ha establecido el sistema de liquidación debería siempre girar la liquidación por el IIVTNU cuando tuviera constancia que ha mediado un incremento real de valor y que éste no es inferior al derivado del sistema forfatario legal. (ii) Caso contrario, caso que tuviera dudas al respecto, debería enviar notificación al obligado tributario a los efectos de que alegara lo que estimara conveniente. (iii) Si de este trámite de alegaciones se dedujera de forma patente que ha mediado un incremento real de valor que no es inferior al derivado del sistema forfatario legal, lo que procede es girar la liquidación tributaria y exigirla incluso por la vía de apremio. (iv) Ahora bien, si de este trámite de alegaciones se dedujera alguna duda sobre la existencia de incremento de valor, lo que procede es acordar de oficio la suspensión del procedimiento liquidatorio. (iv) Mientras que si del mismo trámite de alegaciones, lo que se dedujera es que el incremento real de valor es inferior al derivado del sistema forfatario legal, lo que procede es girar liquidación tomando como base imponible este valor real.

\section{c) Carga de la prueba y elementos probatorios}

En la letra anterior, ya hemos indicado que, según el criterio de la Sentencia interpretativa del TS de 9 de julio de 2018, la carga de la prueba de que no ha existido incremento de valor real corresponde al obligado tributario.

Criterio que compartimos en base a la presunción hominis deducible de la normativa legal reguladora del IIVTNU (según la cual en cada transmisión cabe presumir un incremento de valor) y en base al principio

47 Éste es el sistema adoptado por los Ayuntamientos de Barcelona y de l'Hospitalet de Llobregat, incluso antes de que se dictara Sentencia inerpretativa del TS de 9 de julio de 2018. 
REALA. Nueva Época - N.o 11, Abril-Septiembre 2019 - ISSN: 1989-8975 - DOI: 10.24965/reala.v0i11.10579 - [Págs. 156-183]

Efectos de la declaración de inconstitucionalidad parcial del IIVTNU tras la sentencia interpretativa dictada por el tribunal supremo... Joan Pagès i Galtés

de facilidad probatoria (según el cual, el sujeto pasivo es quien tiene más facilidad para conocer las circunstancias que determinan el eventual incremento que haya experimentado el terreno con motivo de la transmisión -u otro acto susceptible de gravamen-).

Otra cuestión importante es la de determinar qué tipo de indicios son suficientes para probar que no ha mediado incremento patrimonial o, que si lo ha habido, es inferior al que se desprende de la normativa aplicable.

Tal y como también hemos indicado, la Sentencia interpretativa del TS de 9 de julio de 2018, considera aplicable sin fisura alguna el principio de libertad prueba, sosteniendo que basta «cualquier principio de prueba», como por ejemplo, la mera aportación de las escrituras públicas de compraventa, de donación o sucesorias $^{48}$.

\subsection{Medios de defensa a ejercer por los sujetos pasivos}

Los obligados tributarios por transmisiones efectuadas tras la publicación en el $B O E$ de 15 de mayo de 2017 de la STC 59/2017 pueden verse afectados por la misma en este sentido:

I. Si el Ayuntamiento acuerda suspender el procedimiento en los términos que hemos expuesto en el anterior subapartado 6.2.b) ya se solventa la situación del contribuyente que considera que su transmisión no está sujeta al IIVTNU. Y, paralelamente, si el Ayuntamiento gira liquidación tomando como base el incremento real de valor acreditado por el contribuyente, también se solventa la situación de éste al considerar que su incremento de valor es inferior al que se desprende del sistema forfatario previsto en el TR de la LRHL.

II. Si el Ayuntamiento no adopta estas medidas y continúa exigiendo el tributo como si aún no hubiese recaído declaración de inconstitucionalidad, entendemos que el contribuyente está legitimado para promover las siguientes actuaciones diferenciando según el Ayuntamiento exija el impuesto en régimen de autoliquidación o en régimen de liquidación:

a) El Ayuntamiento exige el impuesto en régimen de autoliquidación (al amparo del art. 110.4 TR de la LRHL).

(i) Si aún no se ha presentado la autoliquidación, el contribuyente lo que puede hacer es presentarla acompañada de un escrito en el que se acredite que no existe incremento real o, que aún existiendo, éste en inferior al que se desprende del sistema forfatario previsto por el legislador. Como que en ambos supuestos le afecta la declaración de inconstitucionalidad, se solicitaría, bien la suspensión del procedimiento hasta que el legislador adecúe el TR de la LRHL a la doctrina constitucional, bien que la liquidación se limite al incremento de valor real.

Así mismo cabe recordar que el contribuyente podrá solicitar el aplazamiento de pago con dispensa total de garantía cuando la deuda sea inferior a 30.000 euros $^{49}$.

(ii) Si ya ha presentado la autoliquidación ajustada al sistema forfatario previsto por el legislador, la Administración no ha girado liquidación y no ha prescrito el derecho a liquidar ni a solicitar la devolución, procede que el contribuyente inste la rectificación de la autoliquidación en los términos previstos por el artículo 126 del RGRI de 2007 (RD 1065/2007, de 27 de julio, por el que se aprueba el Reglamento General de Gestión e Inspección), solicitando la devolución que estime corresponda ${ }^{50}$.

(iii) Si la Administración deniega, explícita o tácitamente, la solicitud del contribuyente, procede presentar el recurso de reposición previo al contencioso-administrativo (cfr. 14.2 TR de la LRHL).

b) El Ayuntamiento exige el impuesto por el sistema de liquidación.

(i) Si se trata de una liquidación que aún no es firme en vía administrativa, lo que procede es presentar alegaciones en el trámite de audiencia (cfr. art. 109.8 LGT) o interponer el correspon-

${ }^{48}$ Este es el criterio que ya se defendió por algunos autores antes de la STS de 9 de julio de 2018 (cfr. M. ALÍAS CANTÓN, 2017b, pág. 33; F. CASANA MERINO, 2017, págs. 158-159).

${ }^{49}$ Cfr. art. 82.2.a) LGT en relación con la Orden 347/2016, de 11 de marzo.

50 De haberse girado liquidación, procederá actuar conforme indicamos en el la próxima letra b.-; mientras que de mediar prescripción procederá instar el procedimiento especial de revisión que examinaremos en el apartado 9. 
diente recurso de reposición previo al contencioso-administrativo (cfr. 14.2 TR de la LRHL) a los efectos de solicitar la suspensión del procedimiento.

Caso de ser desestimada esta solicitud procede ya interponer el recurso de reposición contra la liquidación, o si éste ya ha sido interpuesto, lo que procede es interponer el recurso contencioso-administrativo contra la resolución del recurso de reposición.

También aquí cabe recordar que el contribuyente podrá solicitar el aplazamiento de pago con dispensa total de garantía cuando la deuda sea inferior a 30.000 euros.

(ii) Si se trata de una liquidación que es firme en vía administrativa, se plantea el problema de la eficacia temporal de la declaración de inconstitucionalidad en los términos que examinaremos en el siguiente apartado 7 .

\section{TRANSMISIONES REALIZADAS ANTES DE LA DECLARACIÓN DE INCONSTITUCIONALIDAD}

\subsection{Límites a la eficacia temporal de la declaración de inconstitucionalidad}

Según hemos apuntado en el anterior subapartado 6.1, la discusión sobre la eficacia temporal de las declaraciones de inconstitucionalidad se da sobre su retroactividad. Pasemos a ver los diferentes supuestos:

I. Sentencia firme. Está claro, porque así lo dice el artículo 40.1 de la LOTC que, salvo en los procesos penales o sancionadores, las sentencias declaratorias de inconstitucionalidad de normas, «[...] no permitirán revisar procesos fenecidos mediante sentencia con fuerza de cosa juzgada [...]».

Cuando se trata de sentencia firme, prima el principio de seguridad jurídica frente a los principios constitucionales que el TC considera han sido infringidos por la norma declarada inconstitucional.

II. No sentencia firme. En cambio, lo que no está tan claro es que acontece cuando se trata de situaciones jurídicas sobre los que no ha recaído sentencia judicial firme, pues ni la CE ni la LOTC se ocupan específicamente de este tema lo cual, a nuestro modo de ver, implica que se deja a criterio del TC.

La STC 59/2017 que nos ocupa no dice nada al respecto, salvo que los artículos 107.2 y 110.4 del TR de la LRHL están «expulsados del ordenamiento jurídico, ex origine». A nuestro modo de ver, ello implica lo siguiente:

(i) Cuando se trata de situaciones jurídicas que aún no son firmes en vía administrativa, entendemos resulta inevitable sostener que les afecta plenamente la declaración de inconstitucionalidad y, por ende, que si se acredita que se gravan incrementos de valor total o parcialmente irreales, debe procederse a su suspensión.

(ii) Cuando se trata de situaciones jurídicas que ya son firmes en vía administrativa, se genera un problema interpretativo pues, si bien es cierto que las declaraciones de inconstitucionalidad de normas tienden a tener eficacia retroactiva o efectos ex tunc (desde el origen de la norma declarada inconstitucional), no es menos ciertos que en el ámbito tributario la tendencia es exactamente la contraria, es decir, considerar que la declaración de inconstitucionalidad tiene efecto a futuro (respetando los actos administrativos firmes) ${ }^{51}$.

Reconocemos, junto a ALÍAS CANTÓN, que el principio de seguridad alienta la limitación de las declaraciones de inconstitucionalidad impidiendo que afecten a situaciones jurídicas firmes en vía administrativa ${ }^{52}$. Se da empero la circunstancia que «cuando el tribunal ha querido limitar sus efectos, ha dispuesto la excepción», siendo que en ninguna de las Sentencias que han declarado la inconstitucionalidad parcial del IIVT$\mathrm{NU}$, «no se limitan los efectos de la declaración de inconstitucionalidad». Así lo advierte ARANA LANDíN ${ }^{53}$, para quien es razonable entender que la declaración de inconstitucionalidad «tiene efectos ex tunc». Criterio que compartimos, máxime cuando la STC 59/2017, expulsa explícitamente ex origine los artículos 107.2 y 110.4 del TR de la $\mathrm{LRHL}^{54}$. A nuestro modo de ver -aun cuando el TS todavía no se haya manifestado al

51 Vid. sobre esta temática, A. B. MACHO PÉREZ, 2006, pág. 879.

52 De ahí que M. ALÍAS CANTÓN, 2017, pág. 30, concluya diciendo que «[...] el principio de seguridad jurídica también es de aplicación al presente caso, de tal manera que, no debería ser susceptible de revisión, las situaciones jurídico-tributarias firmes producidas al amparo de la normativa del IIVTNU, que ha sido declarada inconstitucional».

53 S. ARANA LANDÍN, 2018, págs. 101 y 102.

54 Y lo mismo hace la STC 72/2017 respecto a los arts. 175.2, 175.3 y 178.4 de la Norma Foral de Navarra. 
REALA. Nueva Época - N.o 11, Abril-Septiembre 2019 - ISSN: 1989-8975 - DOI: 10.24965/reala.v0i11.10579 - [Págs. 156-183]

Efectos de la declaración de inconstitucionalidad parcial del IIVTNU tras la sentencia interpretativa dictada por el tribunal supremo.. Joan Pagès i Galtés

respecto-, esta contundente manifestación corrobora la voluntad del TC de dotar de eficacia retroactiva a la declaración de inconstitucionalidad.

De este modo entendemos que: (i) En tanto en cuanto no medie sentencia judicial firme, serán revisables todos los pagos efectuados por IIVTNU desde que fue instaurado por la LRHL de 1988. (ii) Revisión que consistirá en adecuarlos a la declaración de inconstitucionalidad que el TC ha dictado sobre los preceptos legales en base a los cuales se efectuaron. (iii) De tal manera que si se acredita que el importe pagado no se adecúa a la doctrina constitucional cabrá solicitar su devolución, por más que estemos ante una situación jurídica firme en vía administrativa.

\subsection{Actuaciones a seguir por la Administración municipal}

Creemos pacífico sostener que cuando se trate de transmisiones de terrenos realizadas antes de la declaración de inconstitucionalidad efectuada por la STC 59/2017, publicada en el BOE de 15 de mayo de 2017: (i) No serán, desde luego, susceptibles de revisión las situaciones jurídicas devenidas firmes por sentencia judicial. (ii) En cambio sí serán susceptibles de revisión las situaciones jurídicas no devenidas firmes ni en vía judicial ni en vía administrativa. (iii) La duda se plantea respecto a las situaciones jurídicas que no siendo firmes en vía judicial, sí lo son en vía administrativa. Aun cuando se trata de una cuestión discutible, nosotros entendemos que igualmente serán susceptibles de revisión, pues las SSTC sobre el IIVTNU no han establecido limitación temporal alguna para los efectos de su declaración de inconstitucionalidad.

En este marco, y en tanto en cuanto no se dicte doctrina jurisprudencial, la opción municipal que estimamos más ajustada a derecho por atender a los principios rectores enunciados en el subapartado 4.2, consiste en mantenerse a la espera de lo que diga el legislador local y, por ende: (i) Suspender, al amparo del artículo 56.3.i) de la LPACAP ${ }^{55}$, la tramitación de los procedimientos de revisión instados por los sujetos pasivos. (ii) Y, por supuesto, no iniciar puramente de oficio -a iniciativa propia- ningún procedimiento de revisión.

\subsection{Medios de defensa a ejercer por los sujetos pasivos}

Los sujetos pasivos por transmisiones efectuadas antes de la publicación en el $B O E$ de 15 de mayo de 2017 de la STC 59/2017 pueden verse afectados por la misma en este sentido:

I. Sentencia firme. Aquellos sujetos pasivo que impugnaron ante los tribunales el gravamen por IIVTNU y han obtenido una sentencia firme no pueden beneficiarse de la declaración de inconstitucionalidad por más que puedan demostrar que su transmisión jurídica ha sido gravada en contra de lo que finalmente ha sido la doctrina constitucional sentada por la STC 59/2017 e interpretada por la STS de 9 de julio de 2018.

II. No sentencia firme. Aquellos sujetos pasivos cuya situación no ha devenido firme en vía judicial tienen posibilidades para impugnar en base a la citada STC 59/2017. Debemos diferenciar estos supuestos:

a) Ha mediado impugnación en vía judicial. Si se trata de un caso que está siendo enjuiciado en vía contencioso-administrativa, entendemos que lo procedente es remitir un escrito al órgano judicial a los solos efectos de dejar constancia de que en el caso concreto que se dirime resulta preceptivo la aplicación de la doctrina sentada por la STC 59/2017.

A nuestro modo de ver, por aplicación del artículo 40.2 de la LOTC ${ }^{56}$, el órgano judicial debería ajustar su resolución a la doctrina constitucional y, por ende, declarar no ajustado a derecho el pago efectuado por IIVTNU en la medida que vulnere dicha doctrina.

b) No ha mediado impugnación en vía judicial. Nos referimos al caso en que, pese haberse efectuado el pago del IIVTNU, no media impugnación judicial. Teóricamente ello acontece en estos dos supuestos:

b.1. Situación jurídica que aún no es firme en vía administrativa.

En este supuesto lo que procede es utilizar los medios ordinarios de impugnación que hemos indicado en el anterior subapartado 6.3): rectificación de la autoliqudación o recurso de reposición contra la liquidación.

55 Ley 39/2015, de 1 de octubre, de Procedimiento Administrativo Común de las Administraciones Públicas.

56 El art. 40.2 LOTC establece: «En todo caso, la jurisprudencia de los Tribunales de Justicia recaída sobre Leyes, disposiciones o actos enjuiciados por el Tribunal Constitucional habrá de entenderse corregida por la doctrina derivada de las sentencias y autos que resuelvan los recursos y cuestiones de inconstitucionalidad». 
REALA. Nueva Época - N.o 11, Abril-Septiembre 2019 - ISSN: 1989-8975 - DOI: 10.24965/reala.v0i11.10579 - [Págs. 156-183]

Efectos de la declaración de inconstitucionalidad parcial del IIVTNU tras la sentencia interpretativa dictada por el tribunal supremo... Joan Pagès i Galtés

b.2. Situación jurídica que ya es firme en vía administrativa.

En este supuesto lo que procede es utilizar los procedimientos especiales de revisión.

En todo caso, como que la pretensión última de los interesados es obtener la devolución de lo pagado por IIVTNU, resulta preceptivo plantearse si estamos ante una devolución de ingresos indebidos.

\section{INGRESOS INDEBIDOS}

\subsection{Calificación}

En el supuesto que nos ocupa entendemos que en la medida que las autoliquidaciones y liquidaciones giradas por el IIVTNU se ajustaban al mandato del legislador, su pago constituía un ingreso debido. Ahora bien, a la par debe aceptarse que, desde el primer momento en que el TC ha declarado la inconstitucionalidad de los preceptos legales que amparaban el pago, éste es susceptible de devenir indebido si así se deduce de la STC.

Siempre según nuestro parecer, no otra cosa acontece cuando ninguna de las Sentencias que nos ocupan (las SSTC 26, 37, 59 y 72/2017) no contemplan ninguna limitación temporal de sus efectos, lo que denuncia que la declaración de inconstitucionalidad tiene efectos ex tunc o ex origine. Criterio que se ve reforzado cuando en las dos últimas Sentencias dictadas (las SSTC 59 y 72/2017) se afirma explícitamente y de forma respectiva, que los artículos 107.2 y 110.4 del TR de la LRHL, así como los artículos 175.2, 175.3 y 178.4 de la Norma Foral de Navarra, están «expulsados del ordenamiento jurídico, ex origine».

Por tanto, y en la línea con lo que ya hemos explicado, entendemos cabe concluir que la ley destinada a adaptar la normativa legal del IIVTNU a la declaración de inconstitucionalidad no puede imponer ninguna limitación temporal a sus efectos.

De aceptarse este criterio tendremos que desde la publicación de las respectivas SSTC 26, 37, 59 y $72 / 2017$, los pagos efectuados por IIVTNU han devenido indebidos en la medida que vulneren la doctrina constitucional en ellas sentada, es decir, en la medida que se hayan gravado incrementos de valor irreales.

El problema, como ya hemos indicado, es que los Ayuntamientos están obligados a actuar de conformidad con lo que en su día establezca el legislador, que es a quien, según el TC, corresponde adaptar la normativa del IIVTNU a su doctrina.

Hasta el momento han sido los Territorios forales quienes han dictado esta normativa ${ }^{57}$. En ella se establece que las modificaciones introducidas no tienen carácter retroactivo sobre los devengos anteriores, ya a la fecha de publicación de la propia norma foral (es el caso de Vizcaya), ya a la fecha de publicación de las respectivas Sentencias del TC (es el caso de Guipúzcoa, Álava y Navarra). Y, en todo caso, que no son aplicables a los actos que hayan adquirido firmeza con anterioridad a tal fecha.

Se observa, pues, que el legislador foral interpreta que la declaración de inconstitucionalidad efectuada por las SSTC 26, 37 y 72/2017 -Guipúzcoa, Álava y Navarra- ${ }^{58}$ no tiene efectos ex tunc. Criterio que, por los motivos expuestos no compartimos ${ }^{59}$, pero es al que deberán estarse los Ayuntamientos de estos territorios históricos en tanto en cuanto el TC no se pronuncie sobre semejante limitación temporal.

Pues bien, cuando se trate de Ayuntamientos de régimen común, al no mediar todavía la pertinente normativa legal de adaptación del IIVTNU a la STC 59/2017, no les resta otro remedio que permanecer a la espera, siendo aquí cuando la opción que consideramos más ajustada a derecho por parte de los Ayuntamientos es que acudan al instituto de la suspensión, suspendiendo la tramitación de todos los expedientes de revisión que se insten por los contribuyentes a los efectos de solicitar la devolución de lo pagado por IIVTNU.

\subsection{Procedimiento de devolución de ingresos indebidos. Prescripción}

El procedimiento de devolución de ingresos indebidos se encuentra regulado a nivel legal en el artículo 221 de la LGT.

57 Relacionada por nosotros en el anterior subapartado 4.2

58 Sobre la normativa foral de Vizcaya no ha recaído declaración de inconstitucionalidad sobre el IIVTNU.

59 En este sentido, S. ARANA LANDíN, 2018, pág. 103 concluye que las Normas forales de Guipúzcoa y de Álava destinadas a adaptar sus respectivas regulaciones legal del IIVTNU a la doctrina constitucional, no se adaptan a la misma en tanto en cuanto contemplan limitaciones temporales a sus efectos. 
REALA. Nueva Época - N.o 11, Abril-Septiembre 2019 - ISSN: 1989-8975 - DOI: 10.24965/reala.v0i11.10579 - [Págs. 156-183]

Efectos de la declaración de inconstitucionalidad parcial del IIVTNU tras la sentencia interpretativa dictada por el tribunal supremo.. Joan Pagès i Galtés

En su apartado 1 enumera los supuestos en que se puede instar, figurando en su letra d) el supuesto relativo a "Cuando así lo establezca la normativa tributaria».

Dentro de este supuesto entendemos encajan todos los casos derivados de la declaración de inconstitucionalidad de una norma tributaria, pues desde el primer momento en que una norma tributaria es inconstitucional, también devienen inconstitucionales los actos dictados a su amparo en la medida que así se desprenda de la propia STC y, por ende, si los ingresos efectuados se amparan en una norma inconstitucional, también devienen inconstitucionales, lo cual, a su vez, determina que sean indebidos ${ }^{60}$. De ahí que, como hemos indicado en el anterior subapartado 8.1, tras las SSTC 26, 37, 59 y 72/2017, deben considerarse que han devenido indebidos los ingresos realizados por IITVNU a raíz de transmisiones que denuncien un mero incremento de valor ficticio.

Un dato de extrema relevancia estriba en que, según los artículos 66.c) y 67.1, párrafo quinto, de la LGT, el derecho a solicitar la devolución de ingresos indebidos prescribe a los «cuatro años» contados «[...] desde el dia siguiente a a aquel en que se realizó el ingreso indebido o desde el día siguiente a la finalización del plazo para presentar la autoliquidación si el ingreso indebido se realizó dentro de dicho plazo; o desde el dia siguiente a aquel en que adquiera firmeza la sentencia o resolución administrativa que declare total o parcialmente improcedente el acto impugnado».

Tratándose de un ingreso que ha devenido indebido a raíz de una STC, entendemos que el plazo de prescripción no debe empezar a computarse desde el día en que se realizó el ingrso o finalizó el plazo para presentar la autoliquidación, pues en estas fechas el ingreso era debido. Por tanto, el plazo deberá computarse desde que adquirió firmeza la STC en base a la cual el ingreso adquirió la condición de indebido. Y esa fecha no es otra que la de publicación de la Sentencia. Siendo éste el dies a quo del plazo de prescripción, el interesado tiene cuatro años contados a partir de la publicación de la STC para instar el procedimiento de devolución de ingresos indebidos. El procedimiento a seguir se basa en los siguientes criterios:

(i) Cuando se trata de actos que no han adquirido firmeza en vía administrativa, ya sabemos que lo procedente es instar el procedimiento de devolución de ingresos indebidos junto a la rectificación de la autoliquidación (cfr. art. 221.4 LGT) o, en su caso, junto al recurso de reposición destinado a que la Administración dicte el correspondiente acto administrativo de reconocimiento de la devolución (cfr. art. 221.2 LGT).

(ii) Ahora bien, cuando se trate de actos que sí han adquirido firmeza lo procedente es instar el procedimiento de devolución de ingresos indebidos en el seno de uno de los procedimientos especiales de revisión que se enumeran en el articulo 221.3 de la LGT. Tema del que acto seguido nos ocupamos en el siguiente apartado 9.

\section{PROCEDIMIENTOS ESPECIALES DE REVISIÓN}

\subsection{Esquema}

El artículo 221.3 de la LGT establece que «Cuando el acto de aplicación de los tributos o de imposición de sanciones en virtud del cual se realizó el ingreso indebido hubiera adquirido firmeza, únicamente se prodrá solicitar la devolución del mismo instando o promoviendo la revisión del acto mediante alguno de los procedimientos especiales de revisión establecidos en los párrafos a), c) y d) del artículo 216 y mediante recurso extraordinario de revisión regulado en el artículo 244 de esta Ley».

De estos supuestos, se advierte que el enumerado en la letra d) del artículo 2016 de la LGT no nos resulta aplicable, pues se refiere al procedimiento de corrección de errores regulado por el artículo 220 de la LGT. En el caso que nos ocupa, el ingreso indebido no deriva de un error material, aritmético o de hecho, sino de una sentencia del Tribunal Constitucional.

Así mismo, tampoco creemos nos resulte aplicable el supuesto contemplado por el artículo 224 de la LGT relativo al recurso extraordinario de revisión susceptible de instarse en vía económico-administrativa porque, independientemente de los problemas que plantea su aplicación en el ámbito local, ninguna de las causas que lo legitiman tienen relación con la declaración de inconstitucionalidad de unos preceptos legales ${ }^{61}$.

60 En este sentido P. CHICO DE LA CÁMARA, 2012, pág. 81, explica que, dejando a salvo los supuestos en que el TC ha establecido lo que se ha venido a denominar «jurisprudencia prospectiva» iniciada a raíz de la STC 55/1989, de 20 de febrero, sobre la inconstitucionalidad parcial de la Ley del IRPF de 1978, «[...] la declaración de inconstitucionalidad y nulidad de una norma por parte del Tribunal Constitucional supone en puridad el reconocimiento judicial de la realización en su momento de un ingreso indebido».

61 Y es que, como explica el Informe de 13 de julio de 2017 emitido por el Consell Tributari del Ayuntamiento de Barcelona, «las sentecias no versan sobre hechos y los documentos siempre recaén sobre estos últimos». 
REALA. Nueva Época - N.o 11, Abril-Septiembre 2019 - ISSN: 1989-8975 - DOI: 10.24965/reala.v0i11.10579 - [Págs. 156-183]

Efectos de la declaración de inconstitucionalidad parcial del IIVTNU tras la sentencia interpretativa dictada por el tribunal supremo... Joan Pagès i Galtés

Por tanto, nos debemos limitar a los procedimientos enumerados en las letras a) y c) del artículo 216 de la LGT que, respectivamente, se refieren a la nulidad de pleno derecho y a la revocación. Empecemos por el procedimiento de revocación.

\subsection{Revocación}

El artículo 219 de la LGT enumera los supuestos en base a los cuales se podrá instar el procedimiento de revocación, refiriéndose uno de ellos a «[...] cuando circunstancias sobrevenidas que afecten a una situación jurídica particular pongan de manifiesto la improcedencia del acto dictado [...]».

A nuestro modo de ver, la declaración de inconstitucionalidad de una ley que deje huérfano de cobertura jurídica a un ingreso tributario es una circunstancia sobrevenida que pone de manifiesto su improcedencia y, por ende, entendemos ajustado a derecho que el contribuyente presente un escrito instando al Ayuntamiento para que inicie de oficio el procedimiento de revocación.

Cabe destacar que, según el artículo 219.2 de la LGT, «La revocación sólo será posible mientras no haya transcurrido el plazo de prescripción». De tal manera que si transcurre el plazo cuatrianual de prescripción contemplado por el artículo 66 de la LGT, ya no podrá instarse el procedimiento de revocación.

En el caso que nos ocupa, ya hemos explicado nuestro criterio consistente en que el plazo de prescripción es de cuatro años a contar desde la publicación de la STC por la que se declara la inconstitucionalidad de los preceptos legales en base a los cuales se ha producido el ingreso.

Pasado este plazo de cuatro años, la única opción que resta al interesado es promover el procedimiento de nulidad de pleno derecho.

\subsection{Nulidad de pleno derecho}

El artículo 217 de la LGT enumera los supuestos en base a los cuales se puede instar la declaración de nulidad de pleno derecho. Se trata de una enumeración taxativa que concluye en su letra g) aludiendo a "Cualquier otro que se establezca expresamente en una disposición de rango legal».

A pesar de que estamos ante una enumeración que debe ser interpretada de forma estricta, entendemos que el caso que nos ocupa encaja en este último supuesto, pues tratándose de la declaración de inconstitucionalidad de una ley, parece claro que, salvo que medie sentencia judicial firme, el TC es el único órgano competente para limitar los efectos de su declaración. Y si de su declaración se desprende que no impone limitación alguna de efectos, parece claro que los ingresos pagados baja la cobertura de una ley declarada inconstitucional, también serán inconstitucionales, siendo que la declaración de inconstitucionalidad implica la nulidad absoluta, de ahí que tenga efectos ex nunc, o ex origine, tal i como dice explícitamente en las SSTC 59 y 72/2017.

El tratarse de un acto viciado de nulidad de pleno derecho, implica que no prescribe la acción para que se declare la nulidad ${ }^{62}$. De tal manera que cualquier contribuyente que haya pagado el IIVTNU (ya mediante acto de liquidación, ya mediante autoliquidación) desde su implantación a raíz de la LRHL de 1988, podrá solicitar la devolución de ingresos indebidos a través del procedimiento de nulidad de pleno derecho.

\subsection{Suspensión del procedimiento y plazo de resolución}

Los procedimientos indicados tienen un plazo máximo para su resolución. Concretamente, en la revocación es de seis meses contados desde la notificación del acuerdo de iniciación del procedimiento (cfr. art. 219.4 LGT) y en la nulidad de pleno derecho el plazo es de un año desde que se presenta la solicitud por el interesado (cfr. art. 217.6 LGT).

$\mathrm{Si}$, de acuerdo con la propuesta que venimos defendiendo, el Ayuntamiento opta como opción más ajustada a derecho, suspender el procedimiento de revisión hasta que el legislador se decida modificar el TR de la LRHL para adaptarlo a la doctrina del TC sobre el IIVTNU, es facil que transcurra el plazo máximo para notificar la resolución.

En este supuesto, el contribuyente tiene dos opciones: (i) Esperar a que el Ayuntamiento dicte resolución expresa; o, (ii) acudir a los tribunales.

62 Cfr. R. GARCÍA DE ENTERRÍA, 1981, pág. 237; J. GARCÍA LUENGO, 2002, pág. 276. 
REALA. Nueva Época - N.o 11, Abril-Septiembre 2019 - ISSN: 1989-8975 - DOI: 10.24965/reala.v0i11.10579 - [Págs. 156-183]

Efectos de la declaración de inconstitucionalidad parcial del IIVTNU tras la sentencia interpretativa dictada por el tribunal supremo.. Joan Pagès i Galtés

En el supuesto de que ni tan siquiera los tribunales reconocieran el derecho a la devolución de ingresos indebidos, se abriría la via de la responsabilidad patrimonial del Estado legislador.

\section{RESPONSABILIDAD PATRIMONIAL Y COMPENSACIONES ECONÓMICAS}

\subsection{Responsabilidad patrimonial instada por los sujetos pasivos}

La doctrina ya se ha ocupado de contemplar la eventual responsabilidad del Estado legislador en el caso que nos ocupa ${ }^{63}$.

De la LRJSP ${ }^{64}$ se deduce que los sujetos pasivos afectados por la declaración de inconstitucionalidad del IIVTNU tan sólo podrán instar la responsabilidad patrimonial del Estado legislador cuando, amén de los tradicionales requisitos materiales ${ }^{65}$ y subjetivos ${ }^{66}$, concurran estos otros requisitos:

a) Requisitos formales. Se establece por la LRJSP como novedad que el sujeto pasivo haya recurrido en vía judicial alegando la inconstitucionalidad del IIVTNU que finalmente ha sido declarada por el TC y que, además, el órgano jurisdiccional le haya desestimado su pretensión mediante sentencia firme ${ }^{67}$.

b) Requisitos temporales. En primer lugar, hemos de ponderar si media o no limitación temporal de los efectos de la declaración de inconstitucionalidad. Por los motivos expuestos en el subapartado 7.1, nosotros entendemos que en el caso que nos ocupa no media limitación temporal alguna, pues la declaración de inconstitucionalidad parcial del IIVTNU tiene efectos ex tunc, retrospectivos. En segundo lugar, advertimos se mantiene el plazo general de prescripción de la acción para reclamar, de tal manera esta acción prescribe al año de haberse publicado la STC en el BOE (cfr. art 67.1 LRJSP). Y, en tercer lugar, tan sólo serán indemnizables los daños producidos en el plazo de cinco año anteriores contados desde la publicación de la sentencia declaratoria de la inconstitucionalidad de la ley ${ }^{68}$. Limitación esta última que, constituyendo una importante novedad de la LRJSP ${ }^{69}$ consideramos no se ajusta a la Constitución ${ }^{70}$.

63 Así, B. MORENO SERRANO, 2017, pág. 7, concluye que «Parece pues que sí habrá responsabilidad del Estado legislador». Si bien, M. ALÍAS CANTÓN, 2017, pág. 32, estima que los requisitos legales «[...] determina que la responsabilidad patrimonial del Estado legislador sea de difícil aplicación al presente caso, al menos de aplicación generalizada».

64 Ley 40/2015, de 1 de octubre, de Régimen Jurídico del Sector Público.

65 Para que nazca la acción de responsabilidad se han de dar los tradicionales requisitos generales de carácter material consistentes en que se haya producido un daño o lesión patrimonial, que el daño sea real y efectivo, que sea ilegítimo o antijurídico y no exista deber jurídico de soportarlo y, además, que exista una relación de causalidad entre la actuación del Estado y el daño provocado. De acuerdo con J. I. MORENO FERNÁNDEZ, 2009, págs. 66 y 67, todos estos requisitos concurren cuando se paga un tributo cuya ley de cobertura ha sido declarada posteriormente inconstitucional.

66 Desde un punto de vista activo, entendemos que la legitimidad para entablar la acción de responsabilidad patrimonial es del sujeto pasivo que ha satisfecho el tributo. $Y$ desde un punto de vista pasivo, entendemos que la acción de responsabilidad patimonial se ha de dirigir contra el ente que ha dictado la ley declarada inconstitucional que, en nuestro caso, es el Estado.

$67 \mathrm{El}$ art. 32.3 y 4 LRJSP establece:

«3, [...] los particulares tendrán derecho a ser indemnizados por las Administraciones Públicas de toda lesión que sufran en sus bienes y derecho como consecuencia de la aplicación de actos legislativos de naturaleza no expropiatoria de derechos que no tengan el deber jurídico de soportar cuando así se establezca en los popios actos legislativos y en los términos que en ellos se especifiquen.

La responsabilidad patrimonial del Estado legislador podrá surgir también en los siguientes supuestos, siempre que concurran los requisitos previstos en los apartados anteriores:

a) Cuando los daños deriven de la aplicación de una norma con rango de ley declarada inconstitucional, siempre que concurran los requisitos del apartado 4.

b) $[\ldots]$. .

4. El art. 32.4 LRJSP establece: «Si la lesión es consecuencia de la aplicación de una norma con rango de ley declarada inconstitucional, procederá su indemnización cuando el particular haya obtenido, en cualquier instancia, sentencia firme desestimatoria de un recurso contra la actuación administrativa que ocasionó el daño, siempre que se hubiera alegado la inconstitucionalidad posteriormente declarada».

${ }^{68} \mathrm{El}$ art. 34.1, segundo párrafo, LRSP, establece: «En los casos de responsabilidad patrimonial a los que se refiere los apartados 4 y 5 del artículo 32, serán indemnizables los daños producidos en el plazo de los cinco años anteriores a la fecha de la publicación de la sentencia que declare la inconstitucionalidad de la norma con rango de ley [...]».

69 Así lo destacan M. A. CARBAJO y J. VEGA, 2018, pág. 7.

70 Y es que semejante plazo quinquenal no tiene ninguna lógica y estimamos ha de reputarse inconstitucional por limitar arbitrariamente el derecho a la indemnización por responsabilidad patrimonial establecido en el art. 106.2 de la Constitución y atentar al principio de seguridad jurídica, pues entendemos que el particular no puede verse negativamente afectado por una circunstancia tan aleatoria e 
REALA. Nueva Época - N.o 11, Abril-Septiembre 2019 - ISSN: 1989-8975 - DOI: 10.24965/reala.v0i11.10579 - [Págs. 156-183]

Efectos de la declaración de inconstitucionalidad parcial del IIVTNU tras la sentencia interpretativa dictada por el tribunal supremo..

Joan Pagès i Galtés

\subsection{Exigencia de compensación económica instada por los Ayuntamientos}

En los apartados precedentes hemos explicado que los sujetos pasivos pueden exigir al Ayuntamiento la devolución de los ingresos por IIVTNU que han devenido indebidos a raíz de la declaración de inconstitucionalidad de la ley dictada por el Estado legislador.

Se da empero la circunstancia que el único responsable de la situación en la que nos encontramos es el Estado legislador, pues es él quien ha dictado la normativa declarada inconstitucional.

En este marco, consideramos que los Ayuntamientos están facultados para exigir que el Estado les compense por todos los perjuicios económicos que hayan de soportar con motivo de la declaración de inconstitucionalidad del IIVTNU, pues de otro modo se atentaría contra el principio de suficiencia financiera de las entidades locales, principio éste que resulta basilar para el cumplimiento del principio de autonomía local.

Téngase en cuenta que el legislador local ya contempla la regla general consistente en la determinación de las fórmulas adecuadas para compensar a las entidades locales de los beneficios fiscales que se establezcan por parte del legislador en los tributos locales (cfr. art. 9.2 TR de la LRHL). Ciertamente el legislador local establecedor de nuevos beneficios fiscales no siempre ha cumplimentado este mandato del TR de la LRHL, pero adviértase que el perjuicio económico que para la hacienda local supone el establecimiento de un beneficio fiscal en sus tributos, parte de una actuación legislativa constitucional en la medida que el nuevo beneficio local se adecúe a la Constitución. En cambio, en el caso ahora examinado, la cuestión es muy distinta, pues se parte exactamente de la premisa inversa en la medida que el perjuicio económico sufrido por la hacienda local deriva de una actuación legislativa que ha sido declarada inconstitucional.

$Y$ es que cuando el legislador establece un nuevo beneficio fiscal en los tributos locales excepcionando el criterio general de la compensación previsto en el artículo 9.2 del TR de la LRHL, los Ayuntamientos ya pueden hacer sus previsiones presupuestarias a los efectos de contemplar que en los ejercicios futuros tendrán un menoscabo de sus ingresos. Previsión que no pueden hacer cuando resulta que a raíz de la declaración de inconstitucionalidad de una norma legal los Ayuntamientos se ven de golpe obligados a devolver unos ingresos que ya han percibido y aplicado en ejercicios pasados.

A nuestro modo de ver, esta singular situación afecta de lleno al principio de suficiencia financiera de las haciendas locales, pues no se trata de obtener menos ingresos a futuro, sino de devolver ingresos ya percibidos en el pasado. Y por tanto, en la medida que los Ayuntamientos se han limitado a exigir el impuesto establecido por el legislador para cumplimentar los principios de suficiencia y autonomía local, el Estado está obligado a compensarles por los perjuicios económicos que les acarree la declaración de inconstitucionalidad de la ley dictada por el propio Estado.

\section{CONCLUSIONES}

1. Tras la LRHL de 1988, posteriormente objeto de refundición por el vigente TR de la LRHL de 2004 , se implantó respecto al IIVTNU un sistema forfatario que, interpretado literalmente: (i) provoca la sujeción a gravamen de transmisiones que no denuncien incremento de valor real; (ii) también provoca que el gravamen a satisfacer por las transmisiones pueda ser incluso superior al incremento de valor real; (iii) y, en todo caso, no permite aportar prueba en contrario del incremento de valor calculado forfatariamente.

2. Este sistema había sido ya denunciado por buena parte de la doctrina científica, alegando que no respetaba el principio de capacidad, pero no fue hasta la crisis económica de 2007 cuando el problema adquirió un nivel práctico significativo, pues se empezaron a dar numerosas situaciones en las que materialmente la transmisión del terreno no había dado lugar a un incremento de valor del terreno o que, si lo había dado, el incremento del valor era inferior al determinado tributariamente y, por ende, que el sistema forfatario previsto por el legislador para cuantificar el Impuesto de plusvalía estaba gravando total o parcialmente plusvalías ficticias, irreales.

3. Ante ello, la mayor parte de las doctrinas científica y de los tribunales entendieron que podía mantenerse la constitucionalidad de la ley si se interpretaba en el sentido que el sistema forfatario previsto por el legislador para determinar la base imponible del IIVTNU constituía una presunción iuris tantum, de tal manera que los contribuyentes podían aportar prueba en contrario a que no había mediado incremento real

imprevisible como el tiempo que puede tardar el TC en la emisión y publicación de sus sentencias declaratorias de la inconstitucionalidad de una ley. Vid. en este sentido C. GARCÍA DE LA ROSA, 2018, págs. 269-271. 
REALA. Nueva Época - N.o 11, Abril-Septiembre 2019 - ISSN: 1989-8975 - DOI: 10.24965/reala.v0i11.10579 - [Págs. 156-183]

Efectos de la declaración de inconstitucionalidad parcial del IIVTNU tras la sentencia interpretativa dictada por el tribunal supremo..

de valor o, en su caso, que el incremento de valor real era inferior al que se determinaba por el sistema legal forfatario.

4. Pero este criterio, a nuestro juicio el más adecuado a derecho, no ha sido compartido por el TC, quien ha sentado doctrina en el sentido que el sistema forfatario previsto por el legislador encierra una ficción jurídica que debe declararse inconstitucional.

5. Hasta la fecha, el TC ha dictado cuatro sentencias por las que se declara la inconstitucionalidad de determinados preceptos reguladores del IIVTNU. Tres afectan a territorios forales: (i) STC 26/2017, de 16 de febrero-Guipúzcoa-; (ii) STC 27/2017, de 1 de marzo, -Álava-; y, (iii) STC 72/2017, de 5 de junio -Navarra.Y una afecta al territorio común: STC 59/2017, de 11 de mayo -TR de la LRHL-. Aun cuando presentan algún ligero matiz de redacción, entendemos que sustancialmente contemplan idéntica doctrina constitucional.

6. La premisa básica de la que parten las sentencias del TC examinadas es que el IIVTNU, tal y como está configurado por el TR de la LRHL y por las Normas Forales impugnadas, es constitucional siempre y cuando no grave incrementos de valor irreales, ficticios. Ello, a nuestro modo de ver, implica que continúan estando sometidos a gravamen los incrementos de valor reales.

7. EI TC impone al legislador la reforma de la ley para adaptarla a la doctrina constitucional. En tanto en cuanto no se produzca tal reforma legal, los Ayuntamientos tienen el grave problema consistente en que: (i) Están obligados a gestionar el tributo; (ii) a tales efectos están obligados a aplicar los preceptos legales reguladores del IIVTNU siempre y cuando se adecuen a la doctrina sentada por el TC; (iii) sin embargo, como el TC exige que esta adecuación venga impuesta por una reforma legal, tenemos que en ausencia de cobertura legislativa la adecuación no puede derivar de una Ordenanza fiscal y, ni que decir tiene, de una práctica gestora municipal.

8. Hasta la fecha, los legisladores forales sí que han dado respuesta al mandato del TC dictando la normativa destinada a adecuar el IIVTNU a la doctrina constitucional. Desde luego que puede discutirse el acierto de su contenido, pero cuanto menos dan seguridad jurídica a los Ayuntamientos gestores del impuesto.

9. En cambio, el legislador de territorio común aún no ha dictado la norma por la que se adecue el TR de la LRHL a la doctrina constitucional sobre el IIVTNU. Ello provoca una situación de extrema inseguridad jurídica que tan sólo en parte se ha solventado tras los criterios interpretativos fijados por la STS de 9 de julio de 2018 respecto a la declaración de inconstitucionalidad parcial del IIVTNU efectuada por la STC 59/2017.

10. Los criterios interpretativos fijados por la STS citada pueden, a nuestro juicio, clasificarse con base a los principios que los justifican.

11. Con base a los principios de seguridad jurídica e interdicción de la arbitrariedad, se explica que la STS fije una doctrina interpretativa que evita disparidad de criterios. En este sentido ya había sido útil la aprobación por parte de los órganos municipales de los criterios a seguir tras la declaración de inconstitucionalidad parcial del IIVTNU efectuada por la STC 59/2017.

12. Con base en el principio de capacidad económica, se explica que la STS considere que no son susceptibles de estar gravados los supuestos en los que no se ha puesto de manifiesto un incremento de valor del terreno.

13. En atención al principio de legalidad y de preferencia de ley en el marco de la doctrina del TC, se explica que la STS considere la constitucionalidad parcial de los artículos 107.1 y 107.2.a) del TR de la LRHL, lo cual implica la aplicación de las reglas reguladoras de la base imponible.

14. Con base en el principio de contribución a los gastos públicos, se explica que la STS admita la exacción del tributo en la medida que la transmisión denuncie un incremento de valor del terreno.

15. En atención al principio de salvaguarda de los derechos y garantías de los obligados tributarios en la gestión tributaria, se explica que la STS interprete la inconstitucionalidad total del artículo 110.4 del TR de la LRHL, en la medida que impide a los sujetos pasivos acreditar la existencia de una situación inexpresiva de capacidad económica.

16. Destacamos que la STS sienta dos criterios relevantes sobre la carga y los medios de prueba: (i) Esta Sentencia interpreta que no ha de ser la Administración quien demuestre que la transmisión del terreno ha generado un incremento de valor, pues la carga de la prueba en materia de sujeción tributaria recae sobre el contribuyente, de tal manera que es éste quien, en su caso, ha de demostrar que la transmisión no denuncia incremento de valor. Criterio que, aun reconociendo singular, estimamos respeta la proporcionalidad procesal por ajustarse al principio de facilidad probatoria. (ii) Esta Sentencia interpreta que los contribuyentes pueden servirse de cualquier medio de prueba admisible en Derecho, como por ejemplo, la mera aportación de las escrituras públicas de compraventa, de donación o sucesorias.. Criterio éste nada singular, pues está en perfecta sintonía con el principio general de libertad de prueba. 
REALA. Nueva Época - N.o 11, Abril-Septiembre 2019 - ISSN: 1989-8975 - DOI: 10.24965/reala.v0i11.10579 - [Págs. 156-183]

Efectos de la declaración de inconstitucionalidad parcial del IIVTNU tras la sentencia interpretativa dictada por el tribunal supremo...

Joan Pagès i Galtés

17. La STS, sin embargo, guarda silencio sobre otros problemas no menos importantes que plantea la declaración de inconstitucionalidad del IIVTNU. Se trata de los criterios interpretativos ignorados por la STS.

18. Así, ni las SSTC sobre el IIVTNU ni la citada STS se pronuncian sobre los supuestos de plusvalías escasas, esto es, de los supuestos en que, si bien el incremento de valor existe, la aplicación del tributo puede absorber en exceso la capacidad económica gravada. A nuestro modo de ver, el principio de interdicción de la confiscatoriedad -íntimamente unido al de capacidad- impone que aun cuando la transmisión denunciara un incremento de valor del terreno, el Impuesto no puede absorber la totalidad de la capacidad económica gravada. Lo cual implica: (i) Por un lado, que el sujeto pasivo tenga derecho a probar que el incremento de valor es inferior al que se desprende de los criterios forfatarios actualmente contemplados por el TR de la LRHL. (ii) Por otro lado, que la normativa que el legislador dicte para adecuar la normativa del IIVTNU a la doctrina constitucional respete el principio de proporcionalidad y, por supuesto, no dé lugar al error de salto consistente en que a un incremento de valor real le pueda corresponder una cuota igual o superior al mismo.

19. Ni las SSTC sobre el IIVTNU ni la citada STS se pronuncian sobre el alcance temporal de la declaración de inconstitucionalidad. A nuestro modo de ver: (i) En tanto en cuanto no medie sentencia judicial firme, serán revisables todos los pagos efectuados por IIVTNU desde que fue instaurado por la LRHL de 1988. (ii) Revisión que consistirá en adecuarlos a la declaración de inconstitucionalidad que el TC ha dictado sobre los preceptos legales en base a los cuales se efectuaron. (iii) De tal manera que si se acredita que el importe pagado no se adecúa a la doctrina constitucional cabrá solicitar su devolución, por más que estemos ante una situación jurídica firme en vía administrativa.

20. En el supuesto que nos ocupa entendemos que en la medida que las autoliquidaciones y liquidaciones giradas por el IIVTNU se ajustaban al mandato del legislador, su pago constituía un ingreso debido. Ahora bien, a la par debe aceptarse que, desde el primer momento en que el TC ha declarado la inconstitucionalidad sin limitación temporal y ex origine de los preceptos legales que amparaban el pago, éste deviene ingreso indebido si no se ajusta a la doctrina constitucional que prohíbe el gravamen de incrementos de valor irreales.

21. Entendemos que el plazo de prescripción para solicitar la devolución de ingresos indebidos es de cuatro años a contar desde la publicación en el BOE de la STC por la que se declara la inconstitucionalidad de los preceptos legales con base en los cuales se ha producido el ingreso.

22. El procedimiento de devolución a seguir es el siguiente: (i) Cuando se trata de actos que no han adquirido firmeza en vía administrativa, lo procedente es instar el procedimiento de devolución de ingresos indebidos junto a la rectificación de la autoliquidación (art. 221.4 LGT) o, en su caso, junto al recurso de reposición destinado a que la Administración dicte el correspondiente acto administrativo de reconocimiento de la devolución (art. 221.2 LGT). (ii) Cuando se trate de actos que sí han adquirido firmeza en vía administrativa lo procedente es instar el procedimiento de devolución de ingresos indebidos en el seno del procedimiento especial de revisión consistente en la revocación (art. 219.2 LGT) o en la nulidad de pleno derecho (art. 217 LGT), cabiendo destacar que este último no se ve afectado por el plazo de prescripción.

23. Acudiendo a la normativa positiva, sabemos que hasta el momento han sido los Territorios forales quienes han dictado la normativa de adaptación del IIVTNU a la doctrina constitucional. En ella se establece que las modificaciones introducidas no tienen carácter retroactivo sobre los devengos anteriores, ya a la fecha de publicación de la propia norma foral (es el caso de Vizcaya), ya a la fecha de publicación de las respectivas Sentencias del TC (es el caso de Guipúzcoa, Álava y Navarra). Y, en todo caso, que no son aplicables a los actos que hayan adquirido firmeza con anterioridad a tal fecha. Se observa, pues, que los legisladores forales interpretan que la declaración de inconstitucionalidad efectuada por las SSTC 26, 37 y 72/2017 -Guipúzcoa, Álava y Navarra- no tiene efectos ex tunc. Criterio que, por los motivos expuestos no compartimos, pero es al que deberán estarse los Ayuntamientos de estos territorios históricos en tanto en cuanto el TC no se pronuncie sobre semejante limitación temporal fijada por el legislador foral.

22. Pues bien, cuando se trate de Ayuntamientos de régimen común, al no mediar todavía la pertinente normativa legal de adaptación del IIVTNU a la STC 59/2017, no les resta otro remedio que permanecer a la espera, siendo aquí cuando la opción que consideramos más ajustada a derecho por parte de los Ayuntamientos es que acudan al instituto de la suspensión, suspendiendo la tramitación de todos los expedientes de revisión que se insten por los contribuyentes a los efectos de solicitar la devolución de lo pagado por IIVTNU.

23. Si, de acuerdo con la propuesta que venimos defendiendo, el Ayuntamiento opta como opción más ajustada a derecho, suspender el procedimiento de revisión hasta que el legislador se decida modificar el TR de la LRHL para adaptarlo a la doctrina del TC sobre el IIVTNU, es fácil que transcurra el plazo máximo 
REALA. Nueva Época - N.o 11, Abril-Septiembre 2019 - ISSN: 1989-8975 - DOI: 10.24965/reala.v0i11.10579 - [Págs. 156-183]

Efectos de la declaración de inconstitucionalidad parcial del IIVTNU tras la sentencia interpretativa dictada por el tribunal supremo... Joan Pagès i Galtés

para notificar la resolución. En este supuesto, el contribuyente tiene dos opciones: (i) Esperar a que el Ayuntamiento dicte resolución expresa; o, (ii) acudir a los tribunales.

24. En el supuesto de que ni tan siquiera los tribunales reconocieran el derecho a la devolución de ingresos indebidos, se abriría para el contribuyente la vía de la responsabilidad patrimonial del Estado legislador con base en el art. 32 LRJSP.

25. Los Ayuntamientos están facultados para exigir al Estado las compensaciones económicas por las devoluciones a los contribuyentes que se vean obligados a realizar con motivo de la declaración de inconstitucionalidad del IIVTNU, pues de otro modo se atentaría contra el principio de suficiencia financiera de las entidades locales, principio éste que resulta basilar para el cumplimiento del principio de autonomía local.

\section{BIBLIOGRAFÍA}

AGÚNDEZ FERNÁNDEZ, A. (1990): El Impuesto municipal sobre el Incremento de Valor de los Terrenos de Naturaleza Urbana. Granada: Comares.

ALÍAS CANTÓN, M. (2017): "Efectos de las sentencias del Tribunal Constitucional que declaran la inconstitucionalidad de diversos artículos del Impuesto sobre el Incremento de Valor de los Terrenos de Naturaleza Urbana", en Crónica Tributaria, núm. 164.

ALÍAS CANTÓN, M. (2017b): "La escritura como prueba para acreditar la depreciación del valor a efectos del IIVTNU", en Quincena Fiscal, núm. 11.

ALONSO GONZÁLEZ, L. M. (1995): "La sentencia del Tribunal Constitucional 221/1992, en materia de impuesto sobre plusvalía: un paso más hacia el distanciamiento del principio de capacidad económica", en Revista de Hacienda Local, núm. 74.

ANGLĖS JUANPERE, B. (2018): "La nueva plusvalía municipal, de momento", en Tributos Locales, núm. 134.

ARANA LANDÍN, S. (2018): "Los primeros intentos de mantenimiento del IIVTNU tras la declaración de inconstitucionalidad: vuelta a la vulneración del principio de capacidad contributiva, de no confiscatoriedad y del derecho de defensa", en Tributos Locales, núm. 134.

BARRIO GALLARDO, A. (2018): "El cálculo de la plusvalía a debate tras su declaración de inconstitucionalidad parcial”, en Quincena Fiscal, núm. 15.

CARBAJO DOMINGO, M. A. y VEGA FELGUEROSO, J. (2018): "La responsabilidad patrimonial en las Leyes 39 y 40/2015", en El Consultor de los Ayuntamientos y de los Juzgados, núm. 6.

CASANA MERINO, F. (1994): El Impuesto sobre el Incremento de Valor de los Terrenos de Naturaleza Urbana. Madrid: Marcial Pons.

CASANA MERINO. F. (2017b): "Los incrementos de valor inconstitucionales en el Impuesto sobre el Incremento de Valor de los Terrenos de Naturaleza Urbana", en Revista de Estudios de la Administración Local y Autonómica, núm. 8. DOI: https://doi.org/10.24965/reala.v0i8.10445.

CUBILLES SÁNCHEZ-POBRE, P. (2017): “EI IIVTNU, ¿llegó por fin el momento de modificarlo?”, en Tributos Locales, núm. 129.

CHECA GONZÁLEZ, C. (2000): Los tributos locales. Análisis jurisprudencial de las cuestiones sustantivas más controvertidas. Madrid: Marcial Pons.

CHICO DE LA CÁMARA, P. (2012): La revisión de actos tributarios en la esfera local. Madrid: Renta Grupo Editorial, (Tributos Locales, monografía núm. 1).

CHICO DE LA CÁMARA, P. (2013): "Pérdidas de valor en el IIVTNU y Principio de Capacidad Económica", en Tributos Locales, núm. 111.

DEL BLANCO GARCÍA, A. y GARCÍA CARRETERO, B. (2015): "Cuestiones controvertidas y propuestas de reforma del IIVTNU", en Tributos Locales, núm. 122.

ENTRENA CUESTA, R. (1981): Curso de Derecho administrativo, vol. I/1. Madrid: Tecnos.

ESEVERRI MARTÍNEZ, E. (1993): "Impuesto sobre el Valor de los Terrenos: de la presunción a la ficción jurídica", en Gaceta Fiscal, núm. 108.

ESEVERRI MARTÍNEZ, E. (1995): Presunciones y legales y Derecho tributario. Madrid: Instituto de Estudios Fiscales.

FALCÓN Y TELLA, R. (1993): "La posible inconstitucionalidad del IIVTNU", en Revista Técnica Tributaria, núm. 21.

FERREIRO LAPATZA, J. J. (1989): "Análisis constitucional de la nueva Ley reguladora de las Haciendas Locales", en Revista de Hacienda Autonómica y Local, núm. 55-56.

GARCÍA DE LA ROSA, C. (2018): "La responsabilidad patrimonial del Estado legislador por declaración de inconstitucionalidad de las Leyes en la Ley 40/2015 del Régimen Jurídico del Sector Público", en Civitas-Revista Española de Derecho Financiero, núm. 191.

GARCÍA FRÍAS, A. (2017): "Reflexiones sobre el presente y el futuro del Impuesto sobre el Incremento de Valor de los Terrenos de Naturaleza Urbana a la luz de las SSTC 57 y 59/2017, de 11 de mayo", en Civitas-Revista Española de Derecho Financiero, núm. 175.

GARCÍA LUENGO, J. (2002): La nulidad de pleno derecho de los actos administrativos. Madrid: Civitas. 
REALA. Nueva Época - N.o 11, Abril-Septiembre 2019 - ISSN: 1989-8975 - DOI: 10.24965/reala.v0i11.10579 - [Págs. 156-183]

Efectos de la declaración de inconstitucionalidad parcial del IIVTNU tras la sentencia interpretativa dictada por el tribunal supremo... Joan Pagès i Galtés

HERNÁNDEZ, A. (1991): "El Impuesto municipal sobre el Incremento de Valor de los Terrenos de Naturaleza Urbana", en La reforma de las Haciendas Locales, t. II. Valladolid: Lex Nova.

LÓPEZ LEÓN, J. (2002): Gestión e Inspección del Impuesto sobre el Incremento del Valor de los Terrenos de Naturaleza Urbana. Madrid: El Consultor.

LÓPEZ LEÓN, J. y VERA MESA, A. J. (2018): "Reflexiones sobre el Proyecto de Ley de modificación del TRLRHL relativo al Impuesto sobe el Incremento de Valor de los Terrenos de Naturaleza Urbana", en Tributos Locales, núm. 135.

MACHO PÉREZ, A. B. (2006): El principio de irretroactividad en derecho tributario, tesis doctoral. Barcelona: Universitat Pompeu Fabra.

MARÍN-BARNUEVO FABO, D. (2017): "Significado y alcance de la declaración de inconstitucionalidad de la regulación del IIVTNU en Guipúzcoa y Álava”, en Revista de Contabilidad y Tributación-CEF, núm. 409.

MARTÍN QUERALT, J. (2017): "Los perfiles siempre litigiosos del Impuesto Municipal de Plusvalía. A propósito de la Sentencia del Tribunal Constitucional de 16 de febrero de 2017", en Carta Tributaria, núm. 25.

MARTÍNEZ-CARRASCO PIGNATELLI, J. M. (2017): "Alcance y efectos de la declaración de inconstitucionalidad parcial de la normativa legal del IIVTNU (ST 59/2017, de 11 de mayo)", en Tributos Locales, núm. 131.

MORENO SERRANO, B. (2012): Impuesto sobre el incremento de valor de los Terrenos de naturaleza urbana. Aspectos más relevantes de su ordenamiento jurídico. Las Rozas: El Consultor de los Ayuntamientos y de los Juzgados.

MORENO SERRANO, B. (2017): "La «plusvalía» al borde del abismo", en El Consultor de los Ayuntamientos y de los Juzgados, núm. 6.

NIETO MONTERO, J. J. (1997): La Gestión de los Impuestos Municipales. Pamplona: Aranzadi.

ORÓN MORATAL, G. (1992): "El Impuesto sobre el Incremento de Valor de los Terrenos de Naturaleza Urbana", en Palau 14, núm. 18.

PAGÈS I GALTÉS, J. (2006): Tratado de ordenanzas fiscales. Madrid: Marcial Pons.

PAGĖS I GALTÉS, J. (2010): "La responsabilidad patrimonial de los entes locales en materia de ordenanzas fiscales", en El Consultor de los Ayuntamientos y de los Juzgados, núm. 22.

PALAO TABOADA, C. (2017): "Por qué yerra el TC en sus sentencias sobre el IIVTNU", en Nueva Fiscalidad, núm. 2.

QUESADA SANTIUSTE, F. (2001): Impuesto sobre el Incremento de Valor de los Terrenos de Naturaleza Urbana. Barcelona: Bayer Hermanos.

REBÉS I SOLÉ, J. E. (1987): “L'Impost municipal sobre l'increment del valor dels terrenys (I)", en Manual de Dret Tributari Local. Barcelona: Escola d'Administració Pública de Catalunya.

RUBIO DE URQUÍA, J. I. (2017): "El Tribunal Constitucional se ha pronunciado sobre la Plusvalía municipal; ahora toca que se pronuncie el legislador", en Tributos Locales, núm. 129.

RUBIO DE URQUÍA, J. I. (2018): "Proposición de Ley del Grupo Parlamentario Popular y reforma del IIVTNU”, en Tributos Locales, núm. 134.

RUBIO DE URQUÍA, J. I. y ARNAL SURÍA, S. (1989): Ley reguladora de las Haciendas Locales. Madrid: Abella.

SÁNCHEZ GALIANA, J. A. (2002): Fiscalidad inmobiliaria en la Hacienda Municipal. Granada: Comares.

SIMÓN ACOSTA, E. (1987): "L'Impost municipal sobre l'increment del valor dels terrenys (III)", en Manual de Dret Tributari Local. Barcelona: Escola d'Administració Pública de Catalunya.

URQUIZU CAVALLÉ, A. (2018): "La tributación de la vivienda de los no residentes en territorio español: análisis y propuestas de reforma normativa en referencia al Impuesto sobre la Renta de no Residente", en Reformando las tenencias de la vivienda. Valencia: Tirant lo Blanch.

VARONA ALABERN, J. E. (2010): "A vueltas con la inconstitucionalidad del impuesto sobre el incremento de valor de los terrenos de naturaleza urbana", en Quincena Fiscal, núm. 18.

VILLCA POZO, M. (2018): "Tributación asequible a la promoción del acceso a la vivienda: propuestas de reforma en los impuestos que gravan la adquisición de la vivienda", en Reformando las tenencias de la vivienda. Valencia: Tirant lo Blanch. 